\title{
Postnatal Changes in $\mathrm{K}^{+} / \mathrm{Cl}^{-}$Cotransporter-2 Expression in the Forebrain of Mice Bearing a Mutant Nicotinic Subunit Linked to Sleep-Related Epilepsy
}

\author{
Alida Amadeo, ${ }^{\mathrm{a} *}$ Aurora Coatti, ${ }^{\mathrm{b} \dagger}$ Patrizia Aracri, ${ }^{\mathrm{b} \dagger}$ Miriam Ascagni, ${ }^{\mathrm{a}}$ Davide lannantuoni, ${ }^{\mathrm{a}}$ Debora Modena, ${ }^{\mathrm{a}}$ \\ Laura Carraresi, ${ }^{d}$ Simone Brusco, ${ }^{\mathrm{b}}$ Simone Meneghini, ${ }^{\mathrm{b}}$ Annarosa Arcangeli, ${ }^{\mathrm{c}}$ Maria Enrica Pasini ${ }^{\mathrm{a}}$ and \\ Andrea Becchetti ${ }^{\mathrm{b}}$ \\ ${ }^{a}$ Department of Biosciences, University of Milano, Via Celoria, 26, 20133 Milano, Italy \\ ${ }^{\mathrm{b}}$ Department of Biotechnology and Biosciences, and NeuroMI-Milan Center of Neuroscience, University of Milano-Bicocca, Piazza della Scienza, 2, \\ 20126 Milano, Italy \\ ${ }^{c}$ Department of Experimental and Clinical Medicine, University of Florence, Largo Brambilla, 3, 50134 Firenze, Italy \\ ¿Dival Toscana Srl, Via Madonna del Piano, 6 - 50019 Sesto Fiorentino, Firenze, Italy
}

\begin{abstract}
The $\mathrm{Na}^{+} / \mathrm{K}^{+} / \mathrm{Cl}^{-}$cotransporter-1 (NKCC1) and the $\mathrm{K}^{+} / \mathrm{Cl}^{-}$cotransporter-2 (KCC2) set the transmembrane $\mathrm{Cl}^{-}$gradient in the brain, and are implicated in epileptogenesis. We studied the postnatal distribution of NKCC1 and KCC2 in wild-type (WT) mice, and in a mouse model of sleep-related epilepsy, carrying the mutant B2-V287L subunit of the nicotinic acetylcholine receptor (nAChR). In WT neocortex, immunohistochemistry showed a wide distribution of NKCC1 in neurons and astrocytes. At birth, KCC2 was localized in neuronal somata, whereas at subsequent stages it was mainly found in the somatodendritic compartment. The cotransporters' expression was quantified by densitometry in the transgenic strain. KCC2 expression increased during the first postnatal weeks, while the NKCC1 amount remained stable, after birth. In mice expressing $\beta 2-V 287 \mathrm{~L}$, the KCC2 amount in layer V of prefrontal cortex (PFC) was lower than in the control littermates at postnatal day 8 (P8), with no concomitant change in NKCC1. Consistently, the GABAergic excitatory to inhibitory switch was delayed in PFC layer V of mice carrying $32-V 287 L$. At P60, the amount of KCC2 was instead higher in mice bearing the transgene. Irrespective of genotype, NKCC1 and KCC2 were abundantly expressed in the neuropil of most thalamic nuclei since birth. However, KCC2 expression decreased by $\mathrm{P} 60$ in the reticular nucleus, and more so in mice expressing $\beta 2-V 287 \mathrm{~L}$. Therefore, a complex regulatory interplay occurs between heteromeric nAChRs and KCC2 in postnatal forebrain. The pathogenetic effect of $\beta 2-V 287 L$ may depend on altered KCC2 amounts in PFC during synaptogenesis, as well as in mature thalamocortical circuits. () 2018 IBRO. Published by Elsevier Ltd. All rights reserved.
\end{abstract}

Key words: ADNFLE, ק2-V287L, GABAergic switch, KCC2, prefrontal cortex, reticular thalamic.

\section{INTRODUCTION}

The $\mathrm{Na}^{+} / \mathrm{K}^{+} / \mathrm{Cl}^{-}$cotransporter-1 (NKCC1) and the $\mathrm{K}^{+} /$ $\mathrm{Cl}^{-}$cotransporter-2 (KCC2) are major regulators of the intracellular $\mathrm{Cl}^{-}$concentration $\left(\left[\mathrm{Cl}^{-}\right]_{\mathrm{i}}\right.$, Kaila et al., 2014a). In developing brains, the comparatively large amount of NKCC1 in neurons and astrocytes causes a high $\left[\mathrm{Cl}^{-}\right]_{\mathrm{i}}$, which maintains the reversal potential of the $\mathrm{GABA}_{\mathrm{A}}$ receptor currents $\left(\mathrm{E}_{\mathrm{GABA}}\right)$ at depolarized values

\footnotetext{
${ }^{*}$ Corresponding author.

E-mail addresses: alida.amadeo@unimi.it (A. Amadeo), a.coatti@campus.unimib.it (A. Coatti), patriziaaracri@yahoo.it (P. Aracri), miriam. ascagni@unimi.it (M. Ascagni), davide.iannantuoni@libero.it (D. lannantuoni), debora.modena@unimi.it (D. Modena), laura.carraresi@divalsrl.com (L. Carraresi), s.brusco@campus.unimib.it (S. Brusco),s.meneghini@campus.unimib.it (S. Meneghini), annarosa.arcangeli@unifi.it (A. Arcangeli), maria.pasini@unimi.it (M. E. Pasini), andrea.becchetti@unimib.it (A. Becchetti).

$\dagger$ These authors equally contributed to the paper.

* ORCID 0000-0002-7581-8339.

Abbreviations: ACh, acetylcholine; ADNFLE, autosomal dominant nocturnal frontal lobe epilepsy; AP, action potential; AP5, D(-)-2-amino-5-phosph ono-pentanoic acid; CNQX, 6-cyano-7-nitroquinoxaline-2,3-dione; CTRL, control transgenic mice not expressing $32-\mathrm{V} 287 \mathrm{~L}$; $\mathrm{E}_{G A B A}$, reversal potential of GABAergic currents; Fr2, frontal area 2; GAD, glutamic acid decarboxylase; $\mathrm{KCC}, \mathrm{K}^{+} / \mathrm{Cl}^{-}$cotransporter-2; nAChR, nicotinic acetylcholine receptor; NKCC1, $\mathrm{Na}^{+} / \mathrm{K}^{+} / \mathrm{Cl}^{-}$cotransporter-1; PB, phosphate buffer; PBS, phosphate-buffered saline; PFC, prefrontal cortex; RT, reticular thalamic nucleus; SS, somatosensory cortex; TH, thalamus; TTX, tetrodotoxin; tTA, tetracycline-controlled transcriptional activator; VB, ventrobasal thalamic complex; VLG, ventral lateral thalamic geniculate nucleus; $V_{\text {rest }}$, resting membrane potential; WT, wild type.
} 
(Ben-Ari et al., 2007). Under these conditions, GABA release produces depolarizing effects that modulate neuronal maturation and synaptogenesis (Ben-Ari et al., 2007; Cancedda et al., 2007). Around birth, KCC2 expression progressively increases. By lowering $\left[\mathrm{Cl}^{-}\right]_{\mathrm{i}}$, KCC2 leads $E_{\text {GABA }}$ to the typical hyperpolarized values observed in the adult brain (Rivera et al., 1999; Kaila et al., 2014a). In murine neocortex, such 'GABAergic switch' occurs during the first two postnatal weeks. Being concomitant with the formation of GABAergic synapses (Takayama and Inoue, 2010), it is thought to regulate the postnatal maturation of neuronal circuits ( $\mathrm{Ge}$ et al., 2006; Ben-Ari et al., 2007).

The balance of abundance and activity of NKCC1 and KCC2 is implicated in epileptogenesis as well as in the compensatory responses observed in hyperexcitable networks (Khirug et al., 2010; Kaila et al., 2014b). In fact, genetic variants of these cotransporters are linked to human idiopathic epilepsy (Kahle et al., 2014; Puskarjov et al., 2014). Epilepsy, however, comprises a heterogeneous spectrum of disorders (Jensen, 2011). The role of NKCC1 and KCC2 has been extensively studied in parietal and temporal lobe epilepsy (Dzhala et al., 2005; Aronica et al., 2007; Pathak et al., 2007; Li et al., 2008; Zhu et al., 2008; Talos et al., 2012; Awad et al., 2016; Karlócai et al., 2016), but not in frontal epilepsy. The latter presents distinct pathophysiological features, particularly in relation to the sleep-waking cycle. In frontal lobe epilepsy, sleep favors focal seizures, but not the occurrence of secondary generalization. The opposite holds in the focal epilepsies originating in other cortical regions (Shouse and Quigg, 2008).

To address these issues, we focused on Autosomal Dominant Nocturnal Frontal Lobe Epilepsy (ADNFLE), the mendelian form of hypermotor sleep-related epilepsy, which is characterized by focal hyperkinetic seizures mainly occurring during non-rapid-eyemovement sleep (Tinuper et al., 2016). ADNFLE is frequently caused by point mutations on genes coding for $\alpha$ or $\beta$ subunits of the neuronal nicotinic acetylcholine receptor (nAChR; Tinuper et al., 2016). In the mammalian neocortex, the most widespread heteromeric nAChR is $\alpha 4 \beta 2$, and the first ADNFLE mutations identified on these subunits were $\alpha 4-S 248 F$ (Steinlein et al., 1995) and $\beta 2-$ V287L (De Fusco et al., 2000). In heterologous expression systems, ADNFLE mutations often increase the $\mathrm{nAChR}$ function, at least in the heterozygous state, by augmenting its sensitivity to the agonists or causing other kinetic alterations (Becchetti et al., 2015). Previous studies on the first conditional murine model of ADNFLE, expressing $\beta 2-\mathrm{V} 287 \mathrm{~L}$ in the brain under control of a tetracycline promoter, suggest that the transgene could exert its effects during synaptogenesis (Manfredi et al., 2009). Mice carrying $32-V 287 \mathrm{~L}$ develop spontaneous epileptiform seizures, mostly occurring during periods of increased delta electroencephalographic activity, which is typical of slow-wave sleep. However, for the epileptic phenotype to manifest, $\beta 2-\mathrm{V} 287 \mathrm{~L}$ must be expressed throughout brain development, until the end of the second postnatal week (Manfredi et al., 2009). These results agree with recent lines of evidence suggesting that several $n A C h R$ subunits, including $\beta 2$, display a peak of expression between the second and third postnatal weeks in neocortex and hippocampus (Mansvelder and Role, 2006; Molas and Dierssen, 2014). It has thus been suggested that $\mathrm{nAChRs}$ regulate synaptogenesis, even though the underlying cellular mechanisms are largely unknown (Molas and Dierssen, 2014). Nonetheless, the spontaneous nAChR activity affects the developmental GABAergic switch in neuronal cultures (Liu et al., 2006). In fact, both $\beta 2$-containing nAChRs (Lozada et al., 2012) and KCC2 (Li et al., 2007; Fiumelli et al., 2013; Puskarjov et al., 2014) are involved in maturation and remodeling of dendritic spines. Moreover, rats expressing another nAChR mutation linked to ADNFLE (i.e., a4S284L) display an altered KCC2/NKCC1 messenger ratio (Yamada et al., 2013). Hence, we hypothesized that an early regulatory link might exist between $\beta 2$-containing nAChRs and the $\mathrm{Cl}^{-}$cotransporters, which could have long-term effects on neocortex circuits and excitability.

The timing of NKCC1 and KCC2 appearance in neocortex and thalamus (TH) was previously studied in rats (Clayton et al., 1998; Yan et al., 2001; Wang et al., 2002; Barthó et al., 2004; Kovács et al., 2014), mice (Hübner et al., 2001; Stein et al., 2004; Takayama and Inoue, 2010; Markkanen et al., 2014), and humans (Hyde et al., 2011; Sedmak et al., 2016). However, no detailed analysis is available in mouse for associative cortices and $\mathrm{TH}$ nuclei, the most relevant regions for a sleeprelated frontal epilepsy. To investigate the interplay between $\alpha 4 \beta 2 \mathrm{nAChRs}$ and the $\mathrm{Cl}^{-} /$cation cotransporters, we first determined the NKCC1 and KCC2 distribution in developing neocortex and TH of wild-type (WT) mice. Next, we studied if the amount of these cotransporters was altered in mice expressing $\beta 2-\mathrm{V} 287 \mathrm{~L}$. The morphological analysis was coupled with a patch-clamp study of $\mathrm{E}_{\mathrm{GABA}}$ time course in prefrontal cortex (PFC) layer $\mathrm{V}$, which is the most susceptible to develop epileptiform activity (Telfeian and Connors, 1998). Our results show that altering the function of $\beta 2$-containing nAChRs affects KCC2 expression during postnatal development, and suggest that this mechanism may contribute to epileptogenesis.

\section{EXPERIMENTAL PROCEDURES}

\section{Animals}

Mice were kept in pathogen-free conditions, with a 12-h light-dark cycle, and free access to water and food. All procedures followed the Italian law (2014/26, implementing the 2010/63/UE) and were approved by the local Ethics Committees and the Italian Ministry of Health. For the morphological analyses of WT mice, we used 33 FVB mice (Harlan) of either sex, at the following embryonic $(E)$ or postnatal $(P)$ days: E14-15 $(n=6), \mathrm{P} 0-2(n=8) ; \mathrm{P} 5(n=2) ; \mathrm{P} 7 \quad(n=4)$; P12$\mathrm{P} 14(n=5) ; \mathrm{P} 19-21 \quad(n=3) ; \mathrm{P} 40-60 \quad(n=5)$. The transgenic strain we used was the S3 line of double transgenic FVB (tTA:Chrnb2V287L) mice, which express $\beta 2-V 287 \mathrm{~L}$ under a tetracycline-controlled transcriptional activator (tTA). These mice were compared with their 
littermates not expressing $\beta 2-\mathrm{V} 287 \mathrm{~L}$, which were either WT or bearing TRE-Chrnb2V287L or PrnP-tTA genotypes (Manfredi et al., 2009). For clarity, mice expressing the transgene are hereafter denoted as $\beta 2-V 287 \mathrm{~L}$, while the control littermates are denoted as controls (CTRL). The morphological analysis was carried out on 14 animals of either sex for each experimental group (CTRL and $\beta 2-\mathrm{V} 287 \mathrm{~L})$, at P8 $(n=6), \mathrm{P} 21$ $(n=6)$, and $\mathrm{P} 60(n=16)$. Patch-clamp recordings were carried out on 15 CTRL (all PrnP-tTA) and $9 \beta 2-V 287 L$ mice, whose age distribution is detailed in the Results. No morphological or electrophysiological difference was observed between sexes.

\section{Brain regions}

For immunohistochemistry and densitometric analyses, by PFC we refer to the entire secondary motor region (also known as M2, or Fr2) in the dorsomedial shoulder of prefrontal cortex. According to Franklin and Paxinos (2008), coronal prefrontal sections were cut between +2.58 and $+1.14 \mathrm{~mm}$ from bregma. For somatosensory cortex (SS), we sampled the extended SS region between +1.98 and $+0.02 \mathrm{~mm}$ from bregma. Thalamic sections for reticular (RT) and ventrobasal (VB) nuclei were prepared between -0.58 and $-1.82 \mathrm{~mm}$ from bregma. For patch-clamp experiments, coronal PFC (Fr2) slices were cut between $+2.68 \mathrm{~mm}$ and $+2.10 \mathrm{~mm}$ from bregma.

\section{Chemicals and drugs}

Chemicals and drugs were purchased from SigmaAldrich, except for $\mathrm{D}(-)$-2-amino-5-phosphono-pentanoic acid (AP5), 6-cyano-7-nitroquinoxaline-2,3-dione (CNQX), and tetrodotoxin (TTX), which were purchased from Tocris Bioscience (UK). Stock solutions of gramicidin D $(100 \mathrm{mg} / \mathrm{ml})$ and CNQX $(20 \mathrm{mM})$ were prepared in dimethylsulfoxide. Stock solutions of GABA, AP5, and TTX were prepared in distilled water, stored at $-20^{\circ} \mathrm{C}$, and diluted daily to the final concentration in our extracellular solution.

\section{Tissue preparation for immunohistochemistry}

Postnatal mice were anesthetized with isoflurane and intraperitoneal $4 \%$ chloral hydrate $(4 \mathrm{ml} / 100 \mathrm{~g}$, for mice younger than $\mathrm{P} 14 ; 2 \mathrm{ml} / 100 \mathrm{~g}$, for older mice), and sacrificed by intracardiac perfusion as described (Aracri et al., 2013). Embryos at E14-E15 were quickly removed from the perfused pregnant mouse (aged P40), and their heads immersed in $4 \%$ paraformaldehyde in phosphate buffer (PB), for $24 \mathrm{~h}$ at $4{ }^{\circ} \mathrm{C}$. Next, brains were removed and stored for 5 to 10 days in the same fresh fixative. Both embryonic and postnatal (until P14) brains were embedded in $5 \%$ agarose. Serial coronal brain sections $(50 \mu \mathrm{m}$ thick) were cut with a Leica VT1000S vibratome.

\section{Primary antibodies}

Anti-NKCC1: T4 monoclonal antibody, originated from human colonic crypt (T84 cell) NKCC1, against the carboxy-terminus M902 to S1212 (Developmental Studies Hybridoma Bank; 1:100). Anti-KCC2: polyclonal, made in rabbit, against the N-terminal His-tag fusion protein, corresponding to residues 932-1043 of rat KCC2 (Millipore; diluted 1:600). Anti-VGAT (vesicular GABA transporter): polyclonal, made in rabbit against the synthetic peptide corresponding to the N-terminal 75-87 amino acids of the rat protein (Synaptic Systems; 1:800). Anti-VGLUT1 (vesicular glutamate transporter type 1): polyclonal, made in rabbit against Strep-TagR-fusion proteins containing the amino acid residues $456-560$ of the rat VGLUT1/BNPI (brainspecific Na1-dependent inorganic phosphate transporter; Synaptic Systems; 1:500). Anti-MAP2 (microtubule-associated protein 2): monoclonal, made in mouse against the rat brain MAP2 (1:1000). Antineurofilament $H$, non-phosphorylated: monoclonal, made in mouse, (SMI32; Sternberger Monoclonals; 1:1000). Anti-GAD67 (glutamic acid decarboxylase type $1 / 67 \mathrm{kDa}$ ): polyclonal, made in goat against the human recombinant glutamic acid decarboxylase type 1, rhGAD1 (aa 2-97) derived from E. coli (R\&D Systems; 1:300).

\section{Immunoperoxidase histochemistry for light and electron microscopy}

The immunoreaction was carried out as reported (Aracri et al., 2010), except that a mild pretreatment with ethanol $(10 \%, 25 \%, 10 \%$ in phosphate buffered saline, PBS) was applied to increase the immunoreagent penetration. Reaction specificity was assessed by negative controls, e.g. omission of primary antiserum. In these cases, no specific staining was observed. Briefly, sections were examined on a Leica DMRB microscope, and images were acquired using a Leica DCF 480 camera coupled to a personal computer. To generate Table 1, two independent observers assessed the cotransporter distribution in different brain regions. At least 3 mice were examined for each developmental stage. We analyzed at least 3-4 sections for each cortical region (PFC, SS), and 5-6 sections representative of the whole rostrocaudal thalamic extension. Several images were acquired per section. For ultrastructural analysis, sections were osmicated and epoxy-embedded after completion of the immunoenzymatic procedure. After polymerization, small areas from cerebral cortex and $\mathrm{TH}$ were cut with a razor blade and glued to blank resin blocks for sectioning with a Reichert ultramicrotome. Ultrathin sections (50-70 nm) collected on $\mathrm{Cu} / \mathrm{Rh}$ grids were counterstained with lead citrate, or left unstained, and examined with a Zeiss LEO912AB electron microscope.

\section{Immunofluorescence histochemistry}

Sections were permeabilized and blocked as described for immunoperoxidase histochemistry. They were next incubated for two nights in a mixture of one/two primary antibodies, after staining with NeuroTrace ${ }^{\mathrm{TM}} \quad(1: 50$, Molecular Probes) and/or before staining with Hoechst (Molecular Probes), as necessary for cytoarchitecture analysis and cell counting. For NeuroTrace ${ }^{\mathrm{TM}}$ staining, sections were treated as previously described (Aracri et al., 2010). After washing the primary antibodies with 
Table 1. Developmental distribution of NKCC1 and KCC2 in the forebrain of WT mouse

\begin{tabular}{|c|c|c|c|c|c|c|c|c|}
\hline & E14-E15 & P0-P2 & & P7 & P19-P21 & & P40-P6c & \\
\hline & $\mathrm{KCC} 2$ & NKCC1 & $\mathrm{KCC} 2$ & KCC2 & NKCC1 & KCC2 & NKCC1 & $\mathrm{KCC} 2$ \\
\hline PFC & $+1-$ & +++ & + & ++ & ++ & +++ & ++ & +++ \\
\hline SS & $+1-$ & +++ & ++ & ++ & ++ & ++ & ++ & ++ \\
\hline TH ant & + & +++ & +++ & ++ & +++ & ++ & +++ & ++ \\
\hline $\mathrm{TH}$ me & $+1-$ & ++ & +++ & ++ & $+1++$ & + & ++ & + \\
\hline TH VB & + & +++ & +++ & +++ & +++ & ++ & +++ & ++ \\
\hline TH RT & ++ & +++ & ++ & + & ++ & $+/++$ & ++ & $+/++$ \\
\hline TH LG & +++ & +++ & +++ & +++ & +++ & +++ & +++ & +++ \\
\hline
\end{tabular}

Semi-quantitative analysis of the distribution of $\mathrm{Cl}^{-}$transporters in different brain regions, at different ages, based on immunohistochemical localization, using anti-NKCC1 or anti-KCC2 antibodies, as indicated. The comparison between neonatal and P40 stages for KCC2 was also carried out by densitometric analysis, with analogous results (not shown). PFC: prefrontal cortex; SS: somatosensory cortex; TH ant: anterior thalamic area; TH me: medial thalamus, i.e., intralaminar and midline nuclei; TH VB: thalamic ventrobasal complex; TH RT: reticular thalamic nucleus; TH LG: lateral geniculate thalamic nuclei (comprising both dorsal and ventral lateral geniculate nuclei).

-: negative; + /-: scarce; + : moderately positive; ++ : positive; +++ : markedly positive.

PBS, sections were incubated in the following mixture of secondary fluorescent antibodies: indocarbocyanine (Cy)2 (Jackson; 1:200), or CF ${ }^{\mathrm{TM}} 488 \mathrm{~A}$-conjugated donkey anti-rabbit IgG (Biotium; 1:200), Cy3-conjugated donkey anti-mouse $(1: 200)$ or RedX-conjugated donkey antigoat (Jackson; 1:200), for $75 \mathrm{~min}$ at room temperature. After rinsing, samples were mounted on coverslips (sometimes after nuclear staining with Hoechst) with PBS/glycerol (1:1 v/v) and inspected with a Leica TCSNT laser scanning confocal microscope, to visualize double or triple fluorescent labeling.

\section{Colocalization and densitometric analysis}

All confocal micrographs were collected at $40 \mathrm{X}$ with a Leica SP2 laser scanning confocal microscope, and analyzed with ImageJ. Identical parameters were used to acquire images from cortical and $\mathrm{TH}$ areas, for the colocalization analysis of NKCC1 with VGAT or VGLUT1, as previously described (Aracri et al., 2013). In brief, nonoverlapping pictures were acquired in at least two different sections for neocortex or $\mathrm{TH}$, so that double immunolabeling was studied in 3 or 4 fields per region in each animal. For two-color colocalization analysis, tissues were excited at 488 and $568 \mathrm{~nm}$. To avoid crosstalk, the fluorescent signals of Cy2 (green) and Cy3 (red) were detected sequentially. Colocalization of NKCC1 with either VGAT or VGLUT1 was determined by generating 2D cytofluorograms (Bolte and Cordelières, 2006) by Leica Confocal software, as shown in Fig. 2E, F. Generation of a binary mask of image data allowed to select in each region certain intensity value pairs in the cytofluorograms, which were labeled as white signals in the original images, to represent merged antigen localization (Fig. 2C, D). For densitometric analysis, cortical layers and $\mathrm{TH}$ nuclei were identified with NeuroTrace ${ }^{\mathrm{TM}}$ and/or nuclear counterstaining; at least three/four distinct images were acquired to sample the different areas. For each animal, the mean fluorescence intensity of each image was divided by the number of neurons therein (counted with ImageJ). The values thus obtained were averaged among animals before plotting. For the densitometric analysis of NKCC1, we selected fluorescent images with low background (as shown in Fig. 8). The degree of colocalization of KCC2 or NKCC1 with different neuronal markers was calculated by comparing the Manders' coefficients, computed with the JACoP plug-in of ImageJ software (Bolte and Cordelières, 2006).

\section{Patch-clamp in brain slices}

Mice were sacrificed after deep isoflurane anesthesia, and brains extracted as reported (Aracri et al., 2013). Coronal sections $(300 \mu \mathrm{m}$ thick) were cut from Fr2 PFC. Experiments were performed at $33-34^{\circ}$. $\mathrm{E}_{\mathrm{GABA}}$ was measured with the perforated patch method. The extracellular solution contained $(\mathrm{mM}): 135 \mathrm{NaCl}, 21 \mathrm{NaHCO}_{3}, 0.6$ $\mathrm{CaCl}_{2}, 3 \mathrm{KCl}, 1.25 \mathrm{NaH}_{2} \mathrm{PO}_{4}, 1.8 \mathrm{MgSO}_{4}, 10 \mathrm{D}$-glucose, aerated with $95 \% \mathrm{O}_{2}$ and $5 \% \mathrm{CO}_{2}(\mathrm{pH} \mathrm{7.4)}$. Pipette contained (mM): $140 \mathrm{~K}$-Gluconate, $5 \mathrm{KCl}, 1 \mathrm{MgCl}_{2}, 2.5$ BAPTA, 10 HEPES, pH 7.25 (adjusted with $\mathrm{KOH}$ ). Gramicidin (up to $20 \mu \mathrm{g} / \mathrm{mL}$ ) was only added to the solution filling the pipette shank. Borosilicate (Science Products) micropipettes (2-3 M $\Omega$ ) were prepared with a P-97 Micropipette Puller (Sutter). GABA was applied onto the cell soma, by pressure ejection through a micropipette connected to a Narishige IM-3 microinjector. The recording apparatus was as described (Aracri et al., 2017). The comparison of the action potential (AP) firing of pyramidal neurons in mice expressing or not $\beta 2-\mathrm{V} 287 \mathrm{~L}$ was carried out in a separate set of experiments. The resting membrane potential $\left(\mathrm{V}_{\text {rest }}\right)$ was measured in open circuit mode soon after patch rupture. Spike-width was measured at half-amplitude between AP threshold and peak. Afterhyperpolarization was calculated as the difference between the most negative potential reached after repolarization and the AP threshold. Capacitance and series resistance (up to $\sim 75 \%$ ) were always compensated. $\mathrm{E}_{\mathrm{GABA}}$ was determined by applying five consecutive 0.5 $\mathrm{s}$ voltage ramps from $-80 \mathrm{mV}$ to $-20 \mathrm{mV}$ (or $-85 \mathrm{mV}$ to $-40 \mathrm{mV}$ ), in either presence or absence of GABA (100 $\mu \mathrm{M})$. The background currents were subtracted from the currents obtained in the presence of GABA. Holding potential was $-68 \mathrm{mV}$. Measurements were carried out in the presence of extracellular TTX $(0.5 \mu \mathrm{M})$, to block voltage-gated $\mathrm{Na}^{+}$currents, AP5 $(50 \mu \mathrm{M})$ and CNQX $(10 \mu \mathrm{M})$, to block ionotropic glutamate receptors. No leak subtraction procedure was ever applied. No correction for junction potentials was applied to the reported values of membrane potential. Data were 
analyzed with Clampfit 10.6 (Molecular Devices), and OriginPro 9.1 (OriginLab).

\section{Statistical analysis}

Data are given as mean values \pm st andard error of the mean. The number of experiments $(n)$ is the number of tested mice. Comparisons between two independent populations were carried out with unpaired Student's $t$-test, after testing for data normality (with a Kolmogorov-Smirnov test), and variance homogeneity (with $F$-test). In case of unequal variances, the Welch's correction was applied. All determinations carried out in cells from the same animal were averaged, to avoid bias from nested data (Aracri et al., 2017). In the figures, $p$ values are indicated by * $(0.01<p \leq 0.05)$ or $* * * \quad(p \leq 0.01)$. Unless otherwise indicated, detailed statistics are given in the figure legends.

\section{RESULTS}

We first studied the overall pattern of postnatal expression of NKCC1 and KCC2 in WT mice, as no previous systematic study is available for mouse forebrain. Next, we investigated the effect of $\beta 2-V 287 L$ expression on the cotransporters' amounts between the second and the third postnatal week (i.e., the critical stages of synaptogenesis), and in adult mice. Because ADNFLE is a sleep-related epilepsy with frequent implication of the frontal regions, we focus our study on both PFC and $\mathrm{TH}$, and use SS as the classical reference cortex.

\section{Distribution of NKCC1 in postnatal cortex and TH of WT mice}

Immunoperoxidase localization of NKCC1 is shown in Fig. 1 for neocortex and $\mathrm{TH}$, at birth (P0-P1) and P19-P21 (i.e., after completion of synaptogenesis). For PFC and SS, representative images are respectively displayed in Fig. $1 \mathrm{~A}, \mathrm{~B}$ (P0-P1), and Fig. 1C, D (P19-P21). NKCC1 was widely distributed in neocortex since birth, with no clear differences among layers. As for $\mathrm{TH}$, the NKCC1 immunoreactivity was stronger and more stable in the anterior and posterior TH nuclei (i.e., the specific nuclei). Examples at P0-P1 and P19-P21 are shown, respectively, in Fig. 1E, F. In general, immunoreactivity resulted stable in the different nuclei up to adult stages.
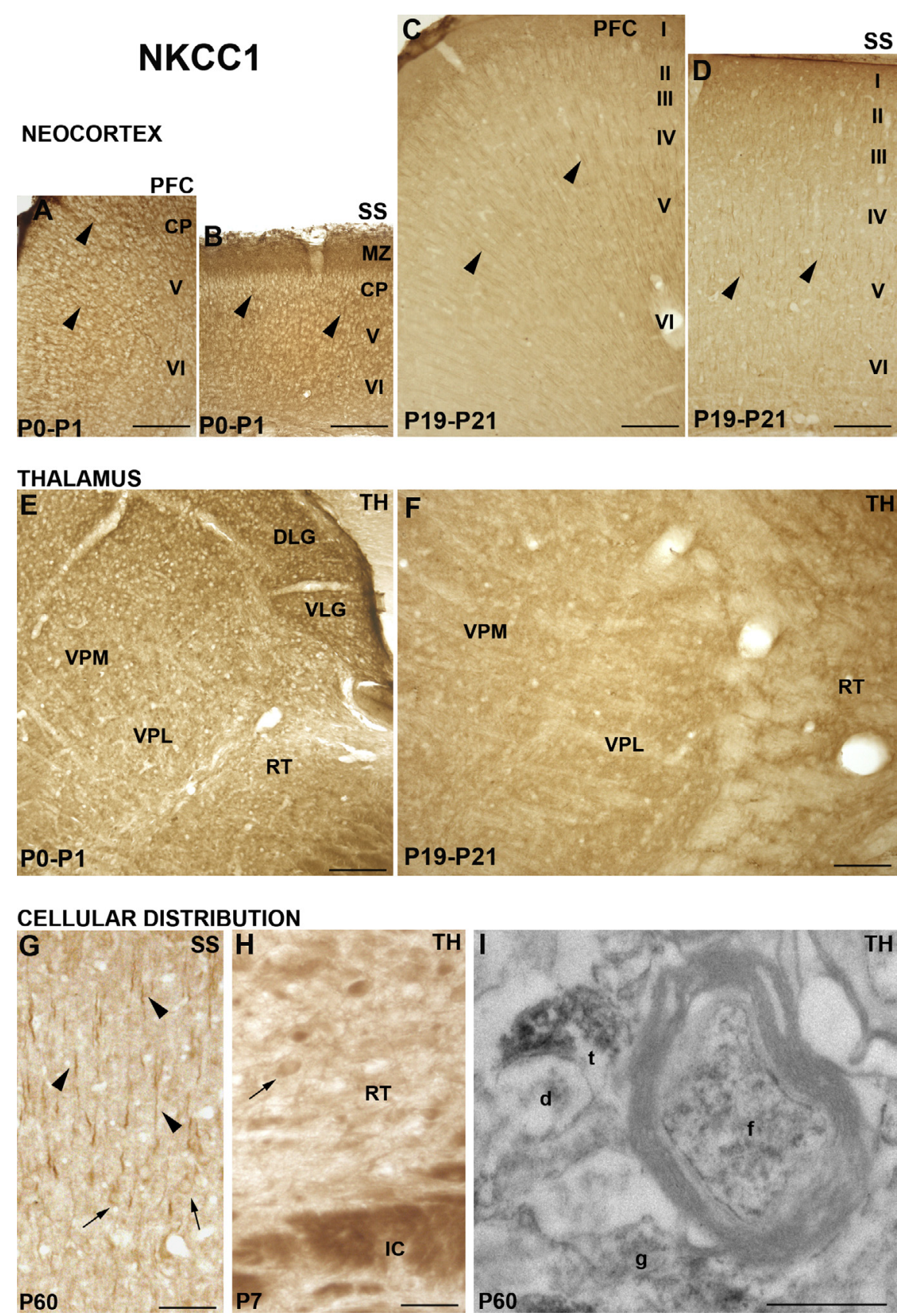

Fig. 1. Topographical and cellular distribution of NKCC1 in developing WT neocortex and thalamus (TH). Immunohistochemical localization of NKCC1 in PFC (A, C), SS (B, D) and TH (E, F) of P0-P1 (A, B, E), and P19-P21 (C, D, F) mice. At both stages, NKCC1 was widely expressed in neocortex and TH, and mainly localized in the apical dendrites of PFC and SS pyramidal cells (arrowheads in A-D). Both in adulthood $(G)$ and during development $(H)$ NKCC1 was found in neurons of both neocortex and TH (arrows in G, H). NKCC1 staining was particularly intense in cortical apical dendrites (arrowheads in G), and in TH thin and thick axonal fibers, such as those of internal capsule (IC). Representative pre-embedding immunoelectron microscopy (TH at P60 in I) showed NKCC1 in the axons of myelinated fibers (f), in some glial processes (g) and in few small synaptic terminals (t) contacting distal dendrites (d). CP, cortical plate; $D L G$, dorsal lateral geniculate thalamic nucleus; $M Z$, marginal zone; $I-V I$, cortical layers; $V L G$, ventral lateral thalamic geniculate nucleus; VPM, ventral posteromedial thalamic nucleus; VPL, ventral posterolateral thalamic nucleus. Scale bars $=150 \mu \mathrm{m}(\mathrm{A}-\mathrm{F}) ; 50 \mu \mathrm{m}(\mathrm{G}) ; 40 \mu \mathrm{m}(\mathrm{H}) ; 0.5 \mu \mathrm{m}(\mathrm{I})$. 
In agreement with previous findings, NKCC1 was generally found in both astrocytes (labeled for GFAP; data not shown) and neurons (Hübner et al., 2001; Yan et al., 2001; Wang et al., 2002). In the neocortex, the marked radial pattern of labeling indicates intense expression in the apical dendrites of pyramidal neurons at both P19-P21 (Fig. 1C, D), and P60 (Fig. 1G), and fainter labeling in cell bodies (Fig. 1G). Such pattern was confirmed by confocal analysis, as indicated by the
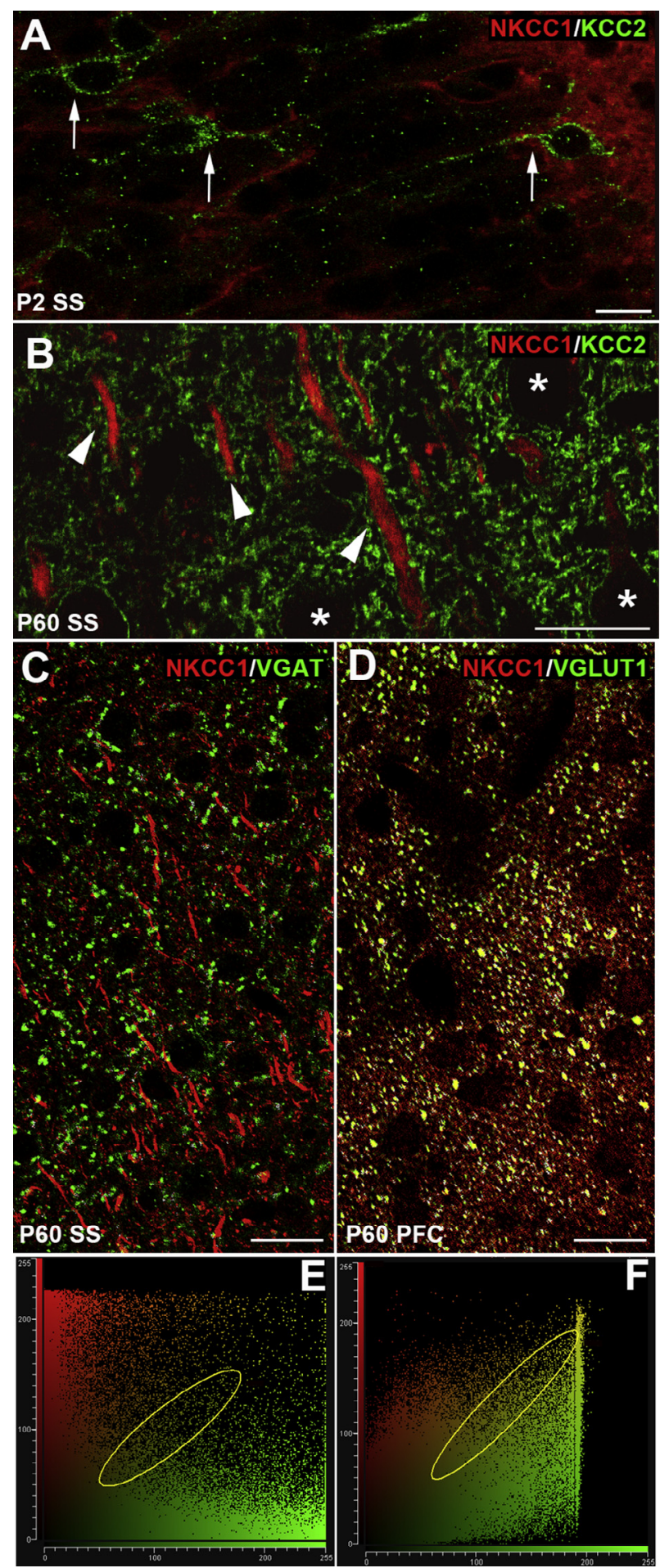

representative images for SS shown in Fig. 2A (P2) and 2B (P60). In $\mathrm{TH}$, strong immunoreactivity was also observed in thin and thick fiber bundles (such as those of internal capsule; Fig. 1H).

Ultrastructural analysis also revealed NKCC1+ synaptic boutons in adult neocortex and $\mathrm{TH}$ (an example is given in Fig. 1I). The neurochemical nature of these synaptic terminals was investigated by studying the colocalization of NKCC1 with either VGAT (which labels GABAergic terminals), or VGLUT1 (which labels the majority of glutamatergic terminals; Graziano et al., 2008). Representative images for the neocortex at $P 60$ are shown in Fig. 2C (NKCC1/VGAT), and 2D (NKCC1/ VGLUT1). The degree of colocalization was estimated by generating the corresponding $2 \mathrm{D}$ cytofluorograms, as illustrated in Fig. 2E (NKCC1/VGAT), and 2F (NKCC1/ VGLUT1). The colocalization puncta are indicated as white spots in Fig. 2C, D. In the mature neocortex, the overlap between NKCC1 and VGAT was always weak. In particular, the calculated M2 Manders' coefficient for Fig. 2C, E was 0.088. A higher degree of colocalization was generally observed for NKCC1 and VGLUT1, particularly in adult PFC (Fig. 2D, F). The calculated M2 coefficient for Fig. 2D, F was 0.8 , indicating that $80 \%$ of the VGLUT1 + synaptic terminals also displayed the NKCC1 signal. On the other hand, in TH nuclei, NKCC1 + NGAT + boutons were only transiently observed in the second postnatal week (data not shown).

\section{Distribution of KCC2 in developing cortex and TH of WT mice}

The KCC2 distribution at different postnatal stages is illustrated in Fig. 3. Clusters of a few KCC2 positive (+) neurons were observed at P0-P1 in PFC layer V, and more abundantly in SS, along with an intense immunoreactivity in the marginal zone (Fig. 3A, B). The overall $\mathrm{KCC} 2$ immunoreactivity was stronger at P19-P21 (Fig. 3C, D). In TH, conspicuous labeling at birth was detected throughout the neuropil, except for

Fig. 2. Double immunofluorescence of NKCC1 with $\mathrm{KCC} 2$, or with synaptic markers, in WT neocortex. Representative images (A, B) combining the NKCC1 (red) and KCC2 (green) signals, in SS. (A) At $\mathrm{P} 2, \mathrm{NKCC} 1$ was found ubiquitously, especially in the neuropil; KCC2 only displayed punctate labeling in the somatodendritic compartment of a fraction of neurons (arrows). (B) At P60, KCC2 and NKCC1 were found in the apical dendrites, but their distribution scarcely overlapped. KCC2 was confined to the cell surface around neuronal cell bodies (asterisks in B) and proximal dendrites (arrowheads in B); in the same dendrites, NKCC1 showed a more diffuse, cytoplasmic distribution. (C) Colocalization of NKCC1 (red) and VGAT (green), in SS at P60. (D) Colocalization of NKCC1 (red) and VGLUT1 (green), in PFC at P60. (E, F) 2D cytofluorograms showing the colocalization puncta in the region of interest (enclosed by the yellow ellipsoid) for NKCC1/VGAT (E) and NKCC1/VGLUT1 (F). These puncta are reported as yellow/white signals in the merged immunolabeling images (C, D), which represent high magnification details covering about one third of the entire fields acquired for colocalization analysis. At P60, very few terminals displayed both NKCC1 and VGAT signal colocalization (C), whereas the degree of colocalization between NKCC1 and VGLUT1 was much stronger (D). Scale bars $=20 \mu \mathrm{m}$. (For interpretation of the references to color in this figure legend, the reader is referred to the web version of this article.) 


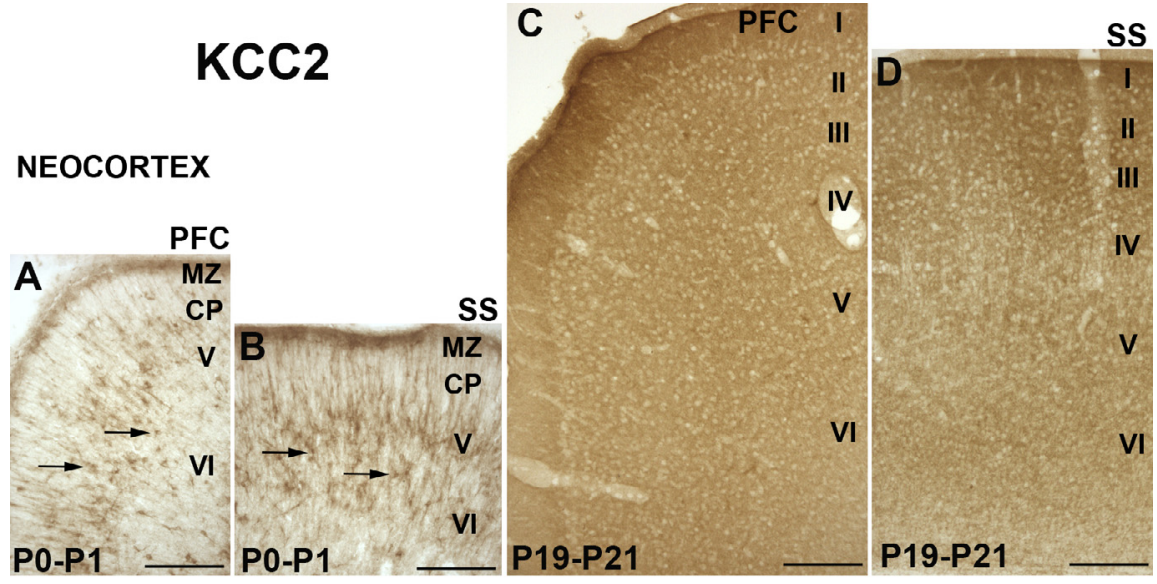

THALAMUS

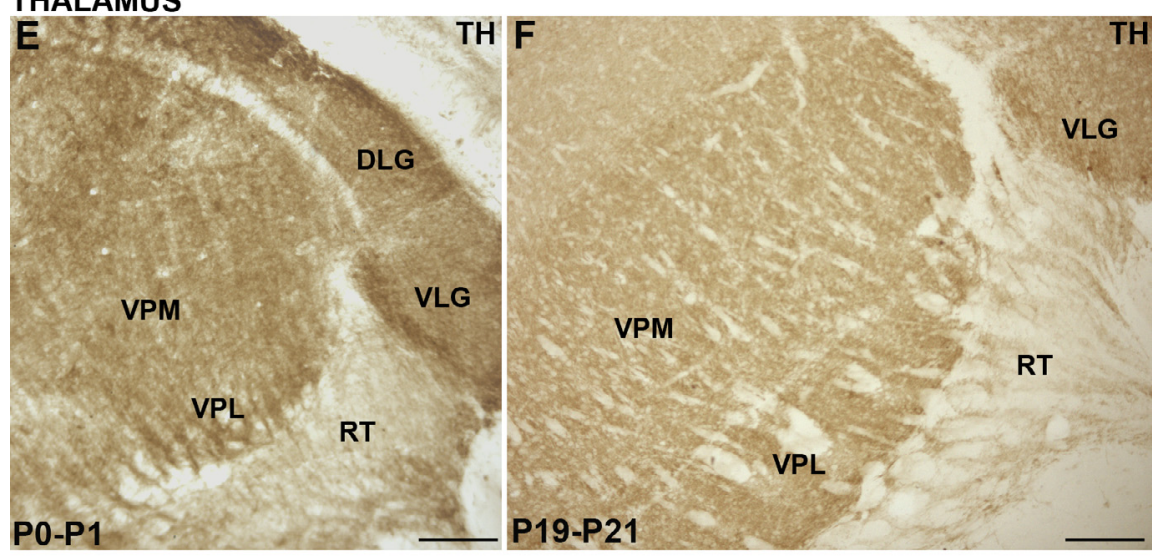

\section{CELLULAR DISTRIBUTION}
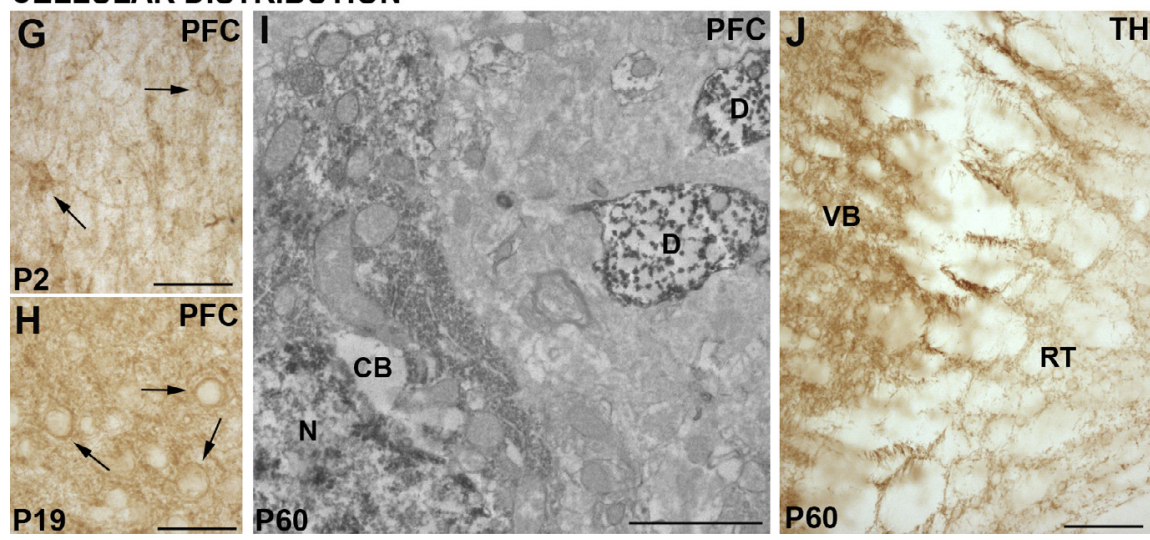

Fig. 3. Topographical and cellular distribution of $K C C 2$ in postnatal WT neocortex and thalamus (TH). Immunohistochemical localization of KCC2 in P0-P1 (A, B, E) and P19-P21 (C, D, F) mice. At birth, KCC2 was mainly confined to the neuronal cell bodies in PFC (A) and SS (B), and clusters of $\mathrm{KCC} 2+$ neurons were mainly found in layer $\mathrm{V}$ (arrows in A, B). At P19-P21, KCC2 was distributed throughout the neuropil in PFC (C) and SS (D). In TH nuclei, KCC2 was already present at P0-P1 in the neuropil of all regions, except RT (E). At P21, KCC2 expression in TH slightly decreased $(F)$, and only a weak immunoreactivity was observed in the lateral and medial borders of RT (F). The immunoperoxidase localization of KCC2 showed its presence only in the neuronal cells and dendrites (G-J). At P2 in PFC, KCC2 was localized in multipolar neurons (arrows in G) Subsequently, KCC2 became distributed in the neuropil and outlined cell membranes (arrows in $\mathrm{H})$, as shown also by immunoelectron microscopical localization (I), where it was exclusively observed in cell bodies (CB) and proximal dendrites (D). In TH (J) KCC2 was mainly expressed by the dendritic neuropil, even in the scarcely labeled RT. $N$, nucleus; $C P$, cortical plate; $D L G$, dorsal lateral geniculate thalamic nucleus; $M Z$, marginal zone; $I-V I$, cortical layers; $V L G$, ventral latera thalamic geniculate nucleus; VPL, ventral posterolateral thalamic nucleus; VPM, ventral posteromedial thalamic nucleus. Scale bars $=150 \mu \mathrm{m}(\mathrm{A}-\mathrm{F}) ; 40 \mu \mathrm{m}(\mathrm{G}, \mathrm{H}) ; 2 \mu \mathrm{m}(\mathrm{I}) ; 80 \mu \mathrm{m}(\mathrm{J})$.
RT (Fig. 3E). The anterior TH group displayed the highest labeling, followed by the posterior group and by the medial/intralaminar group. Such a distribution pattern was preserved at P19-P21 (Fig. 3E, F), when RT was almost devoid of $\mathrm{KCC} 2$ in its central region, whereas the lateral and medial borders displayed a fair labeling (Fig. 3F). These results suggest that $\mathrm{KCC} 2$ is expressed in $\mathrm{TH}$ earlier than in the neocortex. This was confirmed by KCC2 immunofluorescence at E14$\mathrm{E} 15$, which showed a faint $\mathrm{KCC} 2$ signal in frontal and parietal preplate isocortices (Fig. 4A, B), but a more conspicuous labeling in the ventral (especially the ventral lateral geniculate nucleus, VLG, Fig. 4D) and dorsal TH (Fig. 4C, D).

Differently from NKCC1, KCC2 was only expressed in neurons and dendrites (Fig. 3G-J), and its distribution became increasingly polarized during development. In the neocortex, KCC2 was mainly confined to the neuronal cell bodies, during the first postnatal week (Figs. 2A; 3A, B, G; 4E, G). At P19P21 (Fig. 3C, D), the transporter was also found in the dendritic neuropil, and outlined the cell membranes, as can be better appreciated in Fig. 3H, at a higher magnification. A similar pattern was observed in the mature cortex (Figs. 2B; 4F, H). In TH, such distribution shift occurred before birth (Fig. 4C, D), and postnatal neurons showed maximal $\mathrm{KCC} 2$ expression in the neuropil (i.e., dendrites), even in the scarcely labeled RT (Figs. 3J; 4I).

As for the neurochemical nature of $\mathrm{KCC} 2+$ neurons in neocortex, during the first postnatal week both pyramidal neurons and GABAergic GAD67 + neurons (Fig. 4E, G) showed cytoplasmic immunoreactive puncta, probably vesicles, which also spread to proximal dendrites. After P7, KCC2 mainly outlined the membrane of pyramidal neurons (labeled with SMI32; Fig. 4F), whereas in GAD67 + structures (i.e., comprising neuronal cell bodies, processes and puncta), KCC2 was confined to the dendritic shafts (Fig. 4H). A different pattern was observed in TH. The GABAergic neurons, which were mainly 

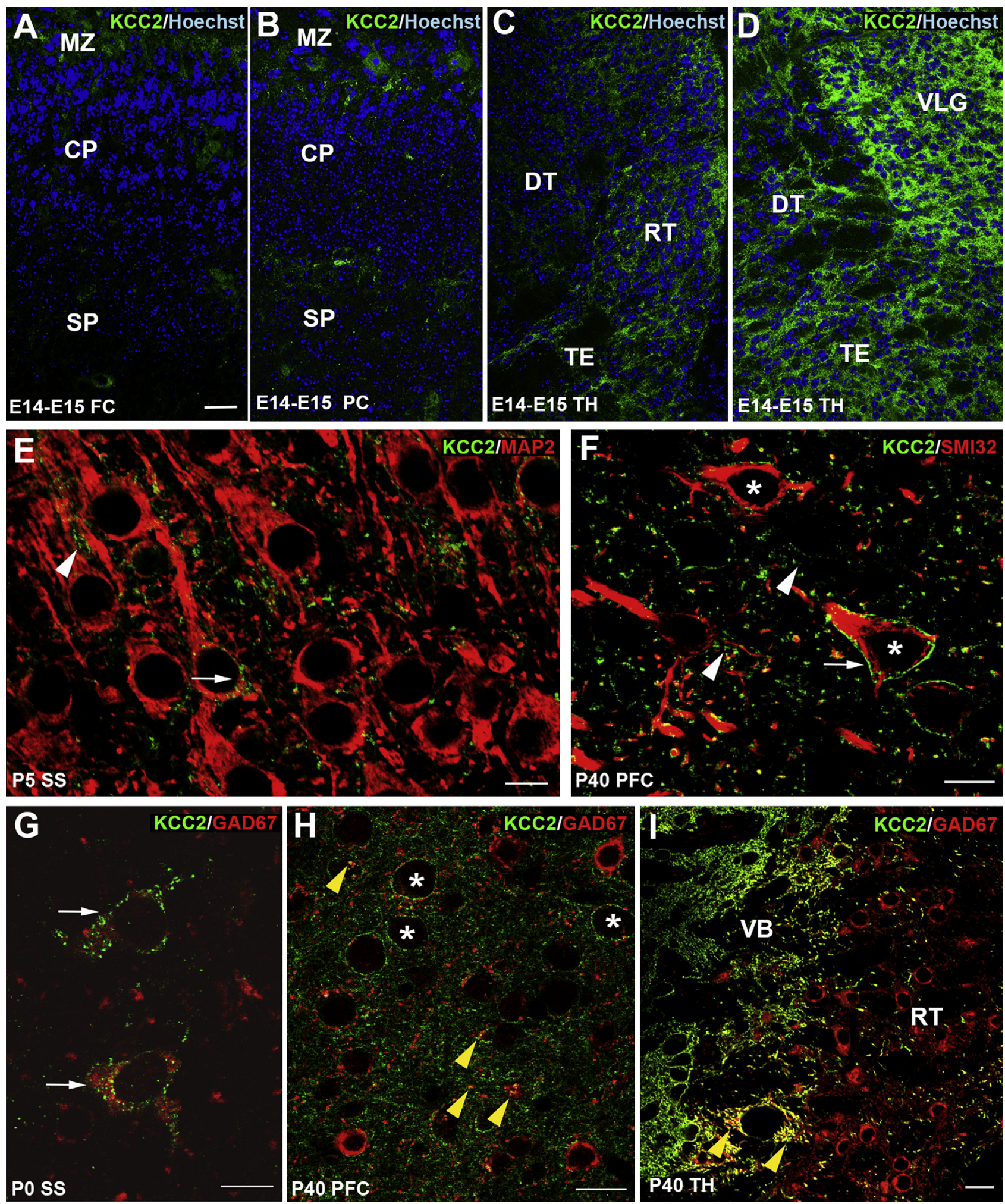

Fig. 4. Localization of $\mathrm{KCC} 2$ in developing WT forebrain. A-D Topographical distribution of KCC2 in prenatal WT forebrain. Immunofluorescence staining for KCC2 (green) in embryonic (E14-E15) cortical (A, B) and thalamic (C, D) tissues; nuclei were stained with Hoechst (blue). KCC2 immunoreactivity was faint in frontal (FC) and parietal (PC) pre-plate isocortex (A, B), but strong in the rostral (C) and caudal (D) thalamic anlage. Double immunofluorescence in SS (E, G), PFC (F, H) and TH (I). Representative images are shown for KCC2 (green) and MAP2 (red) at P5 (E), KCC2 (green) and SMI32 (red) at P40 (F), KCC2 (green) and GAD67 (red) at P0 and P40 (G-J). Around birth, KCC2 was mainly expressed in neuronal cell bodies in the neocortex (arrows in E, G). The MAP2 + pyramidal neurons and the GAD67 + interneurons showed cytoplasmic stained puncta, probably vesicles, spreading to proximal dendrites (E, G). In P40 neocortex, KCC2 was also found in dendrites (white arrowheads in F) and outlined (arrow in F) pyramidal cell membranes (asterisks in F, H), whereas only a small fraction of the GAD67+ dendritic shafts (yellow arrowheads in D) also displayed KCC2 labeling. In TH (I), KCC2 was found in the dendritic neuropil of all TH neurons, and in the medial border of RT, where it displayed colocalization with GAD67 (yellow arrowheads in I). MZ, marginal zone; CP, cortical plate; SP, subplate; DT, dorsal thalamus; TE thalamic eminence. Scale bars $=20 \mu \mathrm{m}$. Scale bars $=20 \mu \mathrm{m}(\mathrm{A}-\mathrm{D}, \mathrm{H}, \mathrm{I}) ; 10 \mu \mathrm{m}(\mathrm{E}, \mathrm{G}) ; 50 \mu \mathrm{m}(\mathrm{F})$. (For interpretation of the references to color in this figure legend, the reader is referred to the web version of this article.) 
concentrated in RT, generally showed a weak KCC2 expression. An exception was constituted by the dendrites of the GAD67 + cells located on the medial border of RT (Fig. 4I). KCC2 was however intensely expressed by the dendritic neuropil of all $\mathrm{TH}$ neurons (Figs. 3E, F, J; 4I).

A semi-quantitative summary of the distribution of NKCC1 and KCC2 in PFC and $\mathrm{TH}$, as obtained by immunohistochemistry at the relevant ages, is reported in Table 1.

\section{The $\beta 2-V 287 L \mathrm{nAChR}$ subunit altered the timing of KCC2 expression}

To define more rigorously the spatiotemporal distribution of $\mathrm{KCC} 2$ at the critical postnatal stages as well as the ratio between $\mathrm{KCC} 2$ and $\mathrm{NKCC} 1$, a densitometric analysis was performed on confocal sections from mice expressing the transgene $(\beta 2-\mathrm{V} 287 \mathrm{~L})$ and the control littermates (CTRL). Because the maturation of synaptic circuits is accompanied by an increase in nAChR subunit expression between the second and the third postnatal weeks (Molas and Dierssen, 2014), we compared P8, P21 and adult (P60) tissue. Sections were labeled for KCC2 and NeuroTrace ${ }^{\mathrm{TM}}$, or Hoechst 33258. The intensity of KCC2 fluorescence was divided by the number of cells identified with either marker.

Fig. 5 shows the results obtained in the neocortex at P8 (Fig. 5A-D), P21 (Fig. 5E-H) and P60 (Fig. 5I-L). The time course of $\mathrm{KCC} 2$ expression in the transgenic strain was consistent with the one observed in WT mice. For example, in CTRL, the densitometric values in PFC layer $\mathrm{V}$ increased by more than $60 \%$ between $\mathrm{P} 8$ $(0.49 \pm 0.014 ; n=3)$ and $\mathrm{P} 60 \quad(0.81 \pm 0.05 ; n=8$; $p<0.01$ with unpaired $t$-test; DF $=9$ ), confirming the progressive increase of $\mathrm{KCC} 2$ amount after birth (cf. Table 1). The main differences between $32-\mathrm{V} 287 \mathrm{~L}$ and CTRL mice were observed in PFC layer $V$, where smaller amounts of KCC2 were observed at P8 in $\beta 2-$ V287L mice (Fig. 5C). Such difference disappeared by P21 (Fig. 5G), and the effect was reversed at $\mathrm{P} 60$, when KCC2 expression was significantly higher in
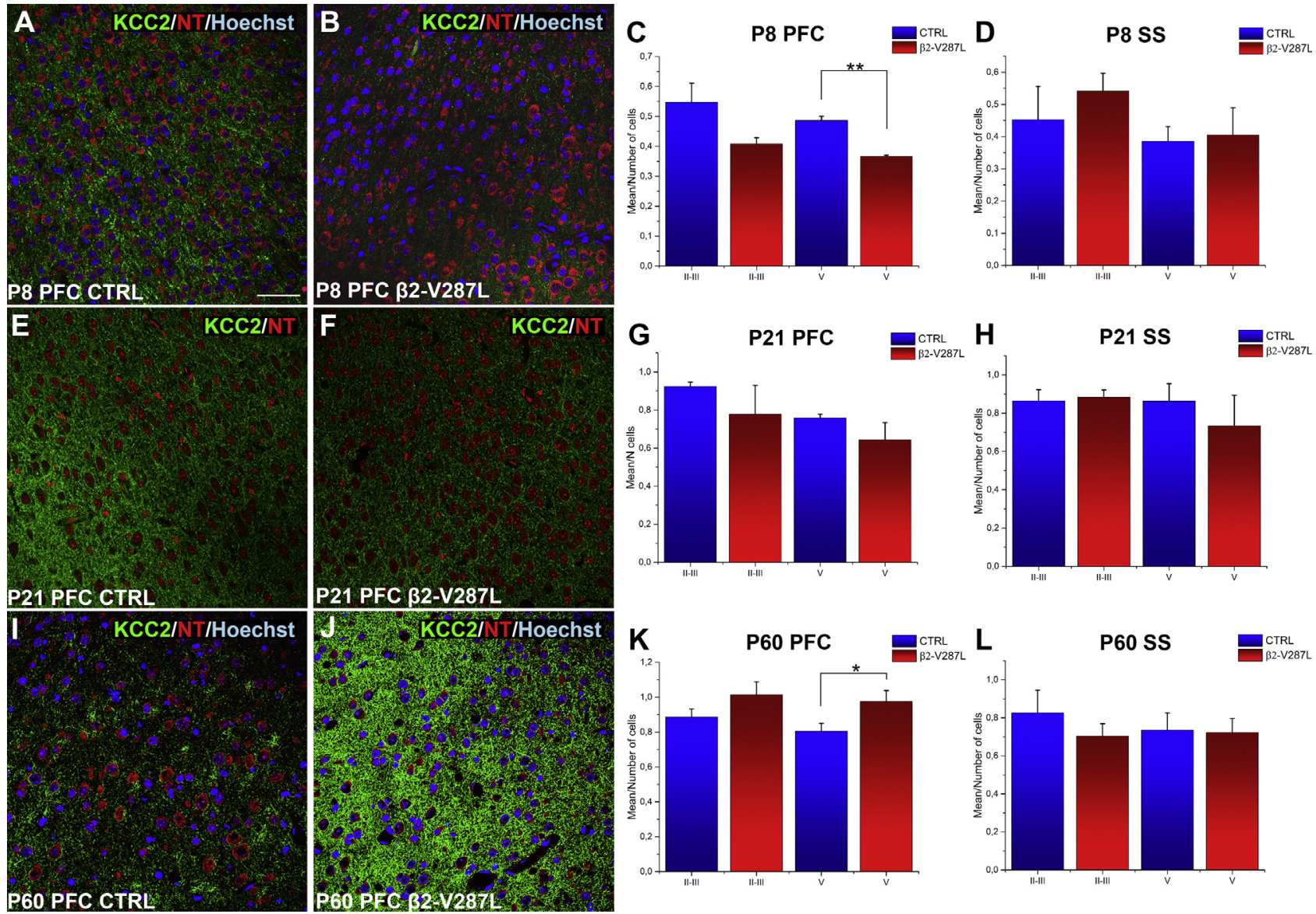

Fig. 5. Effect of $\beta 2-\mathrm{V} 287 \mathrm{~L}$ on $\mathrm{KCC} 2$ expression in neocortex during postnatal development. Immunofluorescence for KCC2 (green) counterstained with NeuroTrace ${ }^{T \mathrm{M}}$ (red; NT) and Hoechst (blue), in PFC layer V of CTRL (A, E, I) and $32-\mathrm{V} 287 \mathrm{~L}(\mathrm{~B}, \mathrm{~F}, \mathrm{~J})$ mice, at the indicated ages. The corresponding densitometric analyses are summarized in the bar graphs for layers II/III and V from P8 $(n=3), \mathrm{P} 21(n=3)$ and P60 $(n=8)$ mice in PFC (respectively $C, G, K$ ), and SS (respectively D, H, L). Bars give average fluorescence intensity values divided by the number of neurons. At P8, KCC2 expression in PFC layer V (C) was significantly lower in $\beta 2$-V287L ( $0.37 \pm 0.004$ vs $0.49 \pm 0.014$ in CTRL; $p<0.01$, with $t$-test; $n=3)(C)$. The opposite was observed at P60, when KCC2 significantly increased in layer $\mathrm{V}$ of $\beta 2-\mathrm{V} 287 \mathrm{~L}(0.98 \pm 0.06$, vs. $0.81 \pm 0.05$ in CTRL; $p<0.05$, with $t$-test; $n=8)(\mathrm{K})$. No statistical difference between genotypes was observed in SS (with $t$-test). Scale bar $=20 \mu \mathrm{m}$. (For interpretation of the references to color in this figure legend, the reader is referred to the web version of this article.) 
32-V287L mice (Fig. 5K). In particular, in layer $\mathrm{V}$, the ratio between the mean KCC2 fluorescence per cell in CTRL and $\beta 2-V 287 L$ decreased from $\sim 1.32$ (P8) to $\sim 0.83$ (P60). At the same ages, no differences were found in the KCC2 amounts in SS (Fig. 5D, H, L).

To test whether the higher KCC2 amount observed in the PFC of adult $\beta 2-V 287 \mathrm{~L}$ mice could be partly ascribed to changes in the GABAergic neuronal populations, we analyzed the colocalization of KCC2 with GAD67. In PFC layer V, at P60 we observed the typical $\mathrm{KCC} 2+$ outlines around the cell bodies of pyramidal neurons (Fig. 4F), in WT (Fig. 4H), CTRL (Fig. 6A-A') and $\beta 2-$ V287L (Fig. 6B-B'). In GAD67+ neurons, KCC2 expression was generally scarce (Fig. 4H, 6A-A'), although some colocalization was observed in $\beta 2-\mathrm{V} 287 \mathrm{~L}$ (Fig. 6B-B'). Hence, the higher KCC2 amount observed in the PFC of adult $\beta 2-V 287 \mathrm{~L}$ mice could partly depend on a different expression in GABAergic neuronal subpopulation. To determine the contribution of GABAergic cells to the total KCC2 increment we
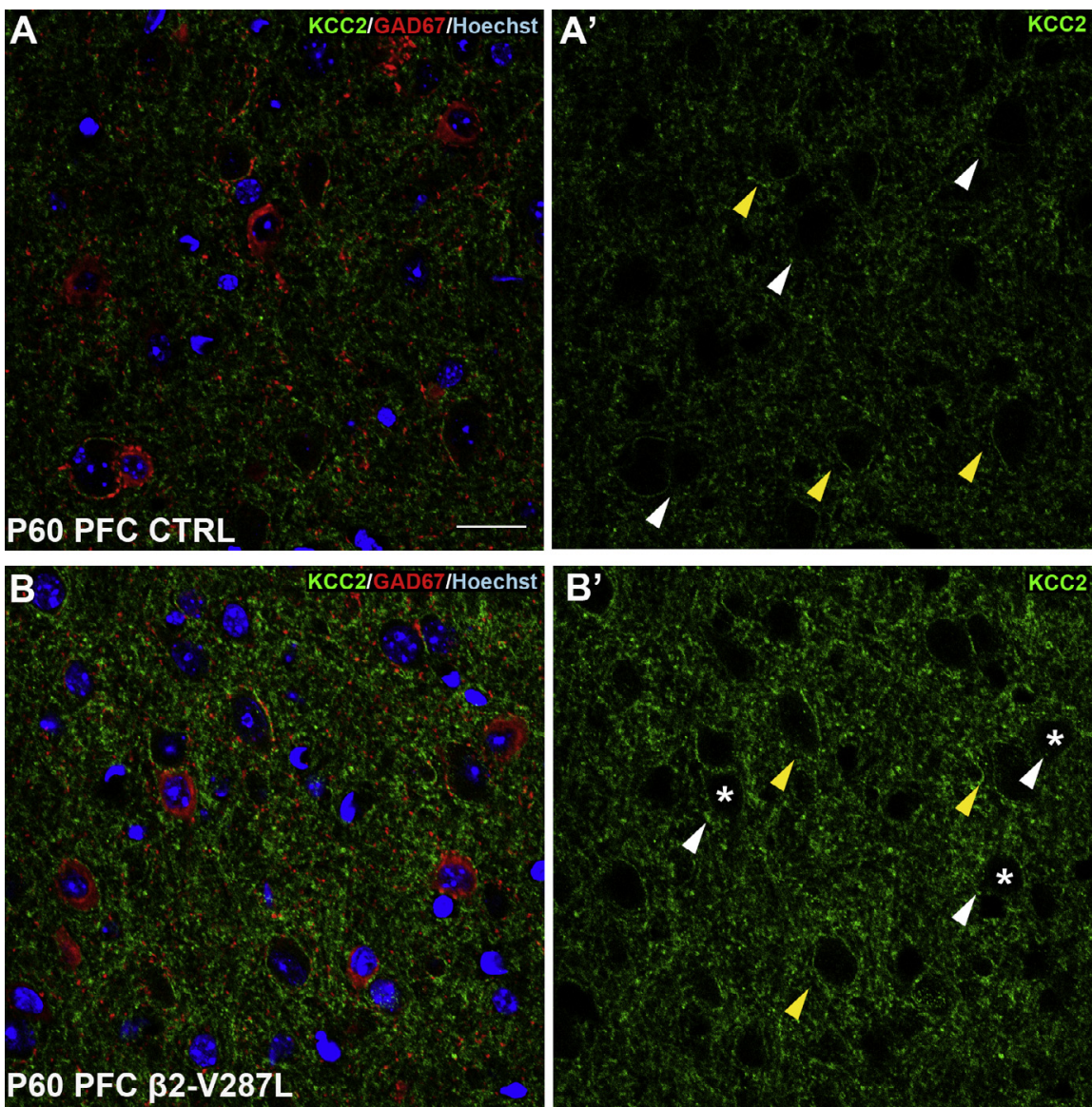

Fig. 6. Colocalization of KCC2 and GAD67 in PFC layer $\mathrm{V}$ of mice expressing or not $\beta 2-\mathrm{V} 287 \mathrm{~L}$ Double immunofluorescence images in PFC layer $\mathrm{V}$ at P60, combining KCC2 (green) and GAD67 (red) localizations with nuclear staining with Hoechst (blue), for CTRL (A) and $\beta 2-V 287 L$ (B). The corresponding single labeling for $K C C 2$ is shown in $\left(A^{\prime}\right)$ for $C T R L$ and $\left(B^{\prime}\right)$ for $\beta 2-V 287 L$. Data represent the results obtained in 3 mice for each genotype. In CTRL, GAD67+ neurons showed a weak KCC2 + staining of somatic neuronal membranes (white arrowheads), but marked KCC2 + outlines of pyramidal neurons' somata (yellow arrowheads). In $\beta 2-V 287 \mathrm{~L}$, the KCC2 immunoreactivity pointed out somatic outlines also on some GAD67 + neurons (asterisks in $\mathrm{B}^{\prime}$ ). Scale bar $=20 \mu \mathrm{m}$. (For interpretation of the references to color in this figure legend, the reader is referred to the web version of this article.) quantified the overall colocalization of $\mathrm{KCC} 2$ and GAD67 (i.e., comprising neuronal cell bodies, processes and puncta). The degree of overlap was defined by $\mathrm{M} 1$ Manders' coefficients, and was not significantly dest; $n=3) ;$ M2 (the fraction of colocaliz ( $0.35333 \pm 0.01154$ in $32-\mathrm{V} 287 \mathrm{~L}(p=0.423$ -test; $n=3$ ).

, our densitometric analysis was focused on RT again, this analysis was consistent with the pattern observed in WT (Table 1). For example, in CTRL, the fluorescence intensity per cell in RT was $(n=3 ; \quad p<0.001$, with unpaired $t$-test; $\mathrm{DF}=4)$. Representative images at $\mathrm{P} 60$ are shown in Fig. 7A, B. In both nuclei, no significant differences were observed between genotypes at early postnatal stages (not shown). However, at P60, the average KCC2 amount decreased in RT by $\sim 20 \%$ in $\beta 2-\mathrm{V} 287 \mathrm{~L}$ mice, compared to CTRL (Fig. 7C). Because in RT the KCC2+ signal was always confined to the GAD67 + dendritic neuropil (Fig. 4I), no analysis of overlap by Manders' coefficients was performed.

\section{B2-V287L did not change NKCC1 expression}

Because $\left[\mathrm{Cl}^{-}\right]_{\mathrm{i}}$ is regulated by both KCC2 and NKCC1, our densitometric analysis was extended to NKCC1, in PFC and $\mathrm{TH}$, at P8 and P60 (Fig. 8), i.e., the regions and ages displaying altered KCC2 amounts in $\beta 2-\mathrm{V} 287 \mathrm{~L}$ mice. To this purpose, we used the T4 antibody against NKCC1, which was also employed for the analysis of developing WT forebrain (Figs. 1 and 2). This antibody was previously used in rodent neocortex, hippocampus and brain stem (Yan et al., 2001; Marty et al., 2002; Ge et al., 2006; Liu and Wong-Riley, 2012) and presents a very good specificity (Chen et al., 2005). Representative images are shown in Fig. 8A, C, E, G. In PFC, NKCC1 expression presented no significant genotype-dependent alteration at P8 (Fig. 8B) and P60 (Fig. 8D). Similar results were obtained in $\mathrm{TH}$ (Fig. 8F, H). 

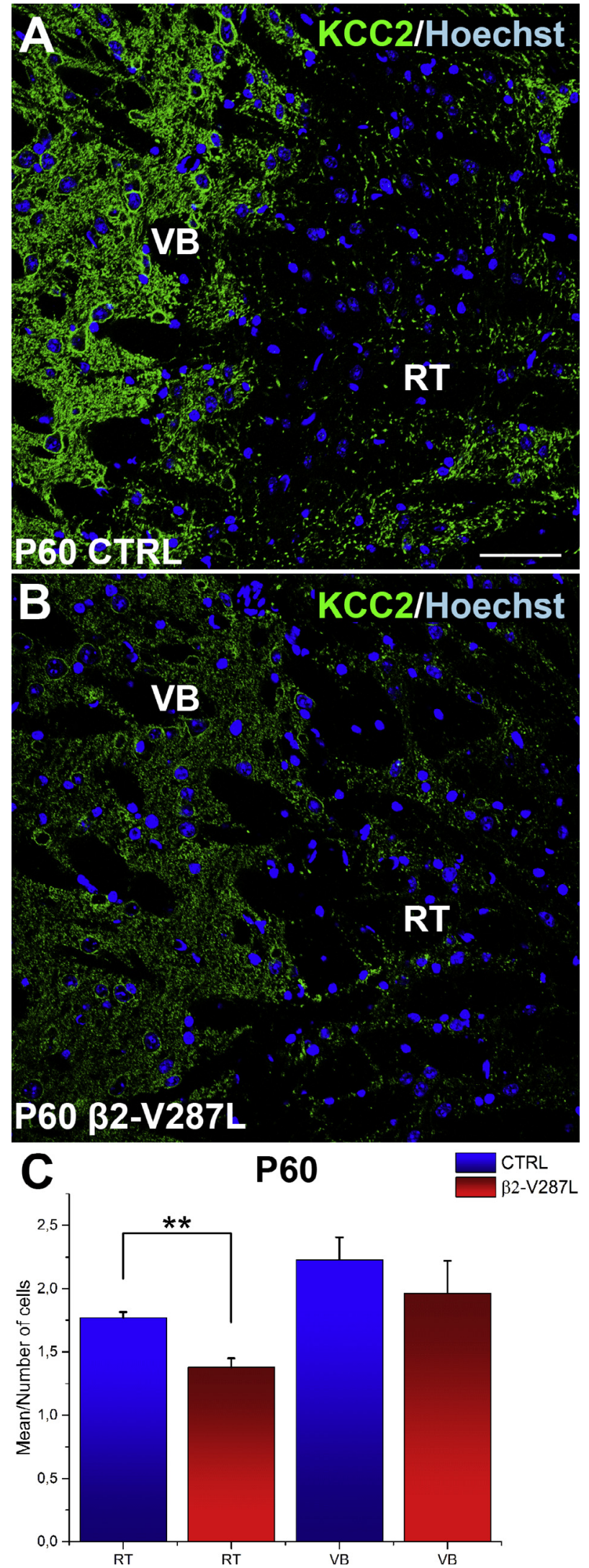

\section{及2-V287L delayed the GABAergic switch in PFC layer V}

The immunofluorescence results show that the retarded expression of KCC2 in PFC layer $\mathrm{V}$ of $\beta 2-\mathrm{V} 287 \mathrm{~L}$ mice was not accompanied by major changes of NKCC1. We thus hypothesized that a lower ratio between the amounts of KCC2 and NKCC1 could be associated with a delayed GABAergic switch. This was tested by measuring $E_{G A B A}$ in pyramidal cells of PFC layer $V$, in brain slices from P8-P9 and adult mice (older than P40). Layer $\mathrm{V}$ is prominent in the premotor Fr2 PFC, and presents large pyramidal neurons that are well recognizable since early postnatal stages. The morphological and electrophysiological properties of these neurons were previously described in detail (Aracri et al., 2010, 2013, 2015). In brief, they display regular spiking with frequencies between 10 and $30 \mathrm{~Hz}$ and moderate adaptation, in the presence of depolarizing stimuli of 150 to $300 \mathrm{pA}$. The electrophysiological features of these cells are reported in Table 2, for a representative sample of P37-P50 mice bearing or not $\beta 2-V 287 L$. No statistical difference was observed between CTRL and $\beta 2$ $\mathrm{V} 287 \mathrm{~L}$ in $\mathrm{V}_{\text {rest }}$, spike width, the ratio between the fourth and the first spike intervals, and after-hyperpolarization (with unpaired $t$-test). Similar values were measured in the second postnatal week (data not shown). In such pyramidal cells, we measured $\mathrm{E}_{\mathrm{GABA}}$ with the perforated patch method, to avoid perturbing $\left[\mathrm{Cl}^{-}\right]_{i}$. Representative GABAergic current traces obtained by applying voltage ramps from -85 to $-40 \mathrm{mV}$ (or -80 to $-20 \mathrm{mV}$, at P8-P9) are displayed in Fig. 9A, for the indicated experimental groups. During brain maturation, $\mathrm{E}_{\mathrm{GABA}}$ progressively hyperpolarized, shifting from $-48.6 \pm 2.03 \mathrm{mV}$ at P8-P9 (15 cells were sampled from 5 mice), to $-58 \pm$ $1.7 \mathrm{mV}$ in adult mice (31 cells, from 10 mice; $p<0.01$, compared with the younger mice; unpaired $t$-test). A similar pattern was observed in adult $\beta 2-V 287 \mathrm{~L}$, where $\mathrm{E}_{\mathrm{GABA}}$ was $-56 \pm 2.5 \mathrm{mV}$ (13 cells, from 5 mice; not statistically different from CTRL, with unpaired $t$-test). However, at $\mathrm{P} 8-\mathrm{P} 9$, in $\beta 2-\mathrm{V} 287 \mathrm{~L}$ mice $\mathrm{E}_{\mathrm{GABA}}$ was more depolarized than in the controls $(-42 \pm 1.65 \mathrm{mV} ; 11$ cells from 4 mice; $p<0.05$, compared with CTRL, with unpaired

Fig. 7. Effect of $\beta 2-\mathrm{V} 287 \mathrm{~L}$ on thalamic expression of $\mathrm{KCC} 2$ at $\mathrm{P} 60$ Representative immunofluorescence images for KCC2 (green) counterstained with Hoechst (blue), in TH nuclei of CTRL (A) and B2V287L (B) mice. The corresponding densitometric analyses are shown in the bar graphs (C), for RT and VB nuclei, as indicated. Data are given as mean fluorescence intensity values divided by the number of neurons. Mice bearing $32-\mathrm{V} 287 \mathrm{~L}$ displayed a decreased KCC2 amount in RT $(1.38 \pm 0.07$, vs. $1.77 \pm 0.04$ in CTRL; $p<$ 0.01 ; $\mathrm{DF}=4$; unpaired two-sample $t$-test with equal variance assumed; $n=3$ ). No significant difference was observed in VB ( $p$ $=0.777 ; \mathrm{DF}=4$; unpaired two-sample $t$-test with equal variance assumed; $n=3$ ). Scale bar $=20 \mu \mathrm{m}$. (For interpretation of the references to color in this figure legend, the reader is referred to the web version of this article.) 

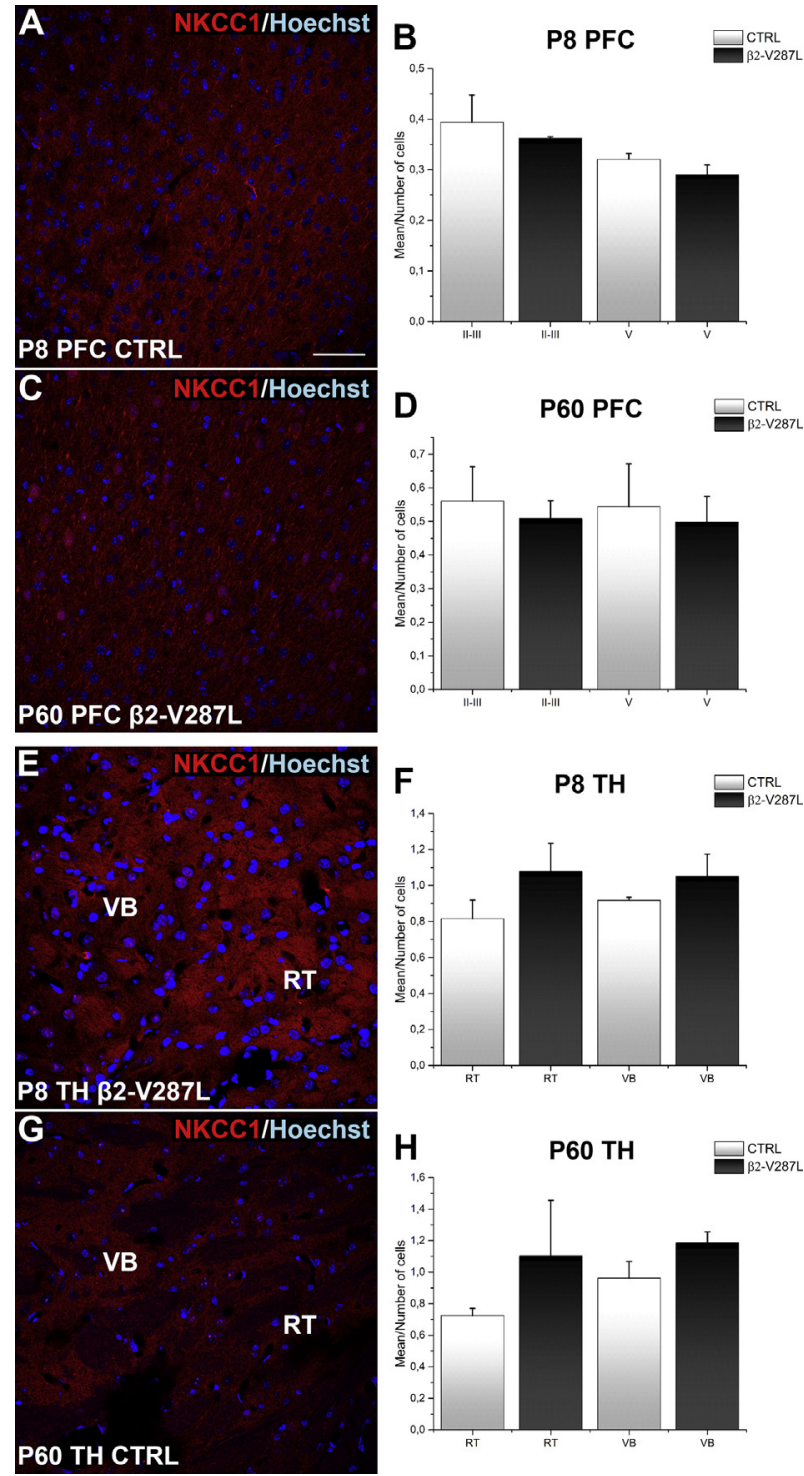

Fig. 8. Effect of $\beta 2-V 287 L$ on NKCC1 expression in developing PFC and $\mathrm{TH}$. Representative images of immunofluorescence for NKCC1 (red) counterstained with Hoechst (blue), in PFC layer $\mathrm{V}(\mathrm{A}, \mathrm{C})$ and TH nuclei $(E, G)$ of CTRL and $\beta 2-V 287 L$ mice, at P8 (A, E) and at P60 $(C, G)$. The corresponding densitometric analyses are summarized in the bar graphs for layers II-III and V from P8 and P60 mice in PFC (respectively $B$ and $D$ ) and in thalamic nuclei $R T$ and $V B(F, H)$, at $P 8$ $(B, F)$ and P60 (D, H). Data are expressed as mean fluorescence intensity divided by the number of neurons. At P8 $(n=3)$ and P60 ( $n$ $=3$ ), no significant differences were observed in NKCC1 expression between CTRL and $32-\mathrm{V} 287 \mathrm{~L}$, in either PFC or TH. For example, in $\mathrm{RT}$ at P60, the mean fluorescence per cell was $0.73 \pm 0.046$ in CTRL, and $1.1 \pm 0.35$ in $\beta 2-\mathrm{V} 287 \mathrm{~L}$ ( $p=0.396$; DF $=2.07$; unpaired $t$-test, assuming unequal variances). In VB, the corresponding values were $0.96 \pm 0.1(\mathrm{CTRL})$ and $1.13 \pm 0.09(\beta 2-\mathrm{V} 287 ; p=0.27$; DF $=4$; unpaired $t$-test, assuming equal variances). Scale bar $=20 \mu \mathrm{m}$. (For interpretation of the references to color in this figure legend, the reader is referred to the web version of this article.)

$t$-test). These data are summarized in Fig. 9B. They show that, in PFC layer $\mathrm{V}$, the time course of $\mathrm{E}_{\mathrm{GABA}}$ hyperpolarization was delayed in $\beta 2-\mathrm{V} 287 \mathrm{~L}$ mice, in agreement with our immunofluorescence results.

\section{DISCUSSION}

We have analyzed the distribution of NKCC1 and KCC2 in the murine neocortex and $\mathrm{TH}$, at different developmental stages. The study was carried out on both WT and a transgenic murine model of ADNFLE. The main finding was that mice carrying the mutant $n A C h R$ subunit $\beta 2-\mathrm{V} 287 \mathrm{~L}$ displayed a delayed surface expression of KCC2 (but not NKCC1) in PFC layer V, during the first postnatal weeks. This led to a transient decrease in the ratio between $\mathrm{KCC} 2$ and $\mathrm{NKCC} 1$, which was accompanied by a retarded GABAergic switch. Moreover, expression of $\beta 2$-V287L was also correlated to changes in KCC2 expression in adult PFC and RT thalamic nucleus.

\section{Regional distribution of NKCC1 and KCC2 in postnatal neocortex}

Previous work in rodents revealed a complex timing and cellular distribution of NKCC1 expression, in different brain regions. Nonetheless, our data agree with the frequent observation that the NKCC1 messenger and protein reach the highest amounts in the neocortex between P7 and P21 (Plotkin et al., 1997; Clayton et al., 1998; Yan et al., 2001; Wang et al., 2002; Dzhala et al., 2005). Whether these levels of expression are retained in the adult is more controversial, as results depend on species as well as on the used antibodies and probes (Plotkin et al., 1997; Clayton et al., 1998; Hübner et al., 2001; Yan et al., 2001; Wang et al., 2002; Dzhala et al., 2005). Our results in both WT and transgenic mice suggest that the surface amount of NKCC1 remains overall stable in the mature PFC.

As for KCC2, at birth it was specifically localized in the marginal zone and infragranular layers. Its expression increased thereafter, and reached the adult distribution by the third postnatal week, in both WT and transgenic mice. This process paralleled the GABAergic switch, which in neocortex and hippocampus is delayed compared to the subcortical structures (Fiumelli and Woodin, 2007; Kovács et al., 2014). Once again, our results broadly agree with previous results in mouse showing that KCC2 increases in postnatal stages, although regional exceptions are observed (Wang et al., 2002; Kovács et al., 2014; Markkanen et al., 2014). They also agree with several non-systematic determinations in rat (Lacoh et al., 2013), and human tissue (Hyde et al., 2011). Moreover, we found KCC2 expression to be more precocious in SS. Together with other observations on more specific markers (Hyde et al., 2011; Aracri et al., 2013), these results support the notion that PFC matures more slowly than other brain regions, which could make it more liable to develop pathologies related to network maturation, such as certain forms of epilepsy and schizophrenia (Hyde et al., 2011; Lacoh et al., 2013; Kaila et al., 2014a; Kovács et al., 2014).

\section{Cotransporters' distribution in thalamic nuclei}

Minor differences were observed in the postnatal amounts of NKCC1 at the tested stages, in both WT and transgenic 
Table 2. Expression of $\beta 2-\mathrm{V} 287 \mathrm{~L}$ did not alter $\mathrm{V}_{\text {rest }}$ and the firing properties of pyramidal cells in PFC layer $\mathrm{V}$

\begin{tabular}{lllll}
\hline & $\begin{array}{l}V_{\text {rest }} \\
(\mathrm{mV})\end{array}$ & $\begin{array}{l}\text { Spike width } \\
(\mathrm{ms})\end{array}$ & 4thspike interval/1stspike interval & $\begin{array}{l}\text { AHP } \\
\mathrm{mV}\end{array}$ \\
\hline CTRL & $-69.4 \pm 0.63$ & $1.52 \pm 0.08$ & $1.8 \pm 0.1$ & $-9.3 \pm 0.49$ \\
$\beta 2-V 287 \mathrm{~L}$ & $-68.9 \pm 0.52$ & $1.51 \pm 0.05$ & $1.9 \pm 0.09$ & $-9.3 \pm 0.59$ \\
\hline
\end{tabular}

Mice were aged P37-P50. The ratios between the fourth and the first spike interval were calculated in the presence of a $200 \mathrm{pA}$ stimulation, and average firing frequency of $\sim 15 \mathrm{~Hz}$. No statistical difference was observed between mice expressing or not $\beta 2-\mathrm{V} 287 \mathrm{~L}$ (with unpaired $t$-test). AHP: after-hyperpolarization.
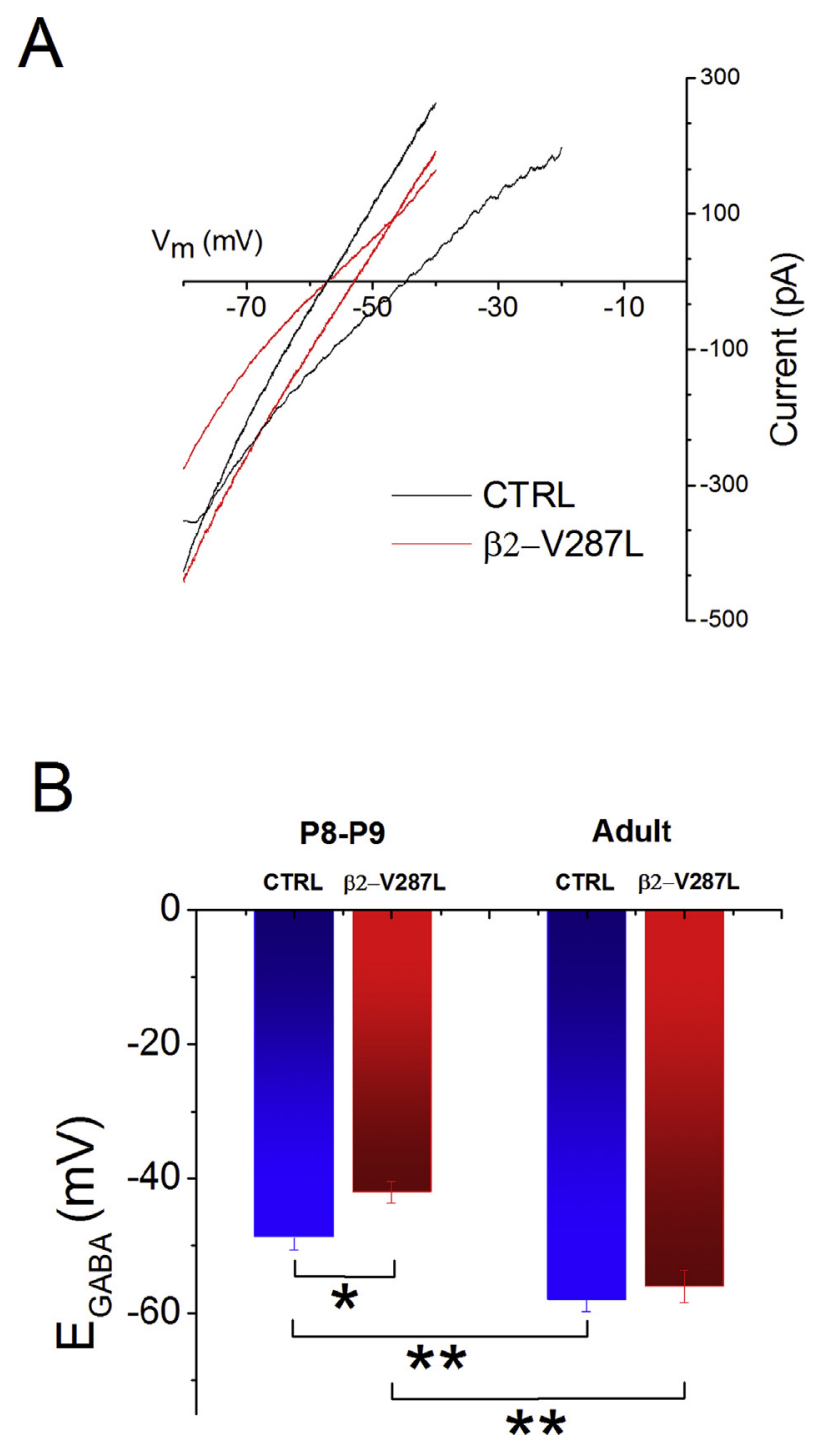

Fig. 9. The effect of $\beta 2-V 287 L$ on the GABAergic switch. The timecourse of $E_{G A B A}$ was followed by perforated-patch experiments. Layer $\mathrm{V}$ pyramidal neurons were studied at P8-P9 or adult stages. (A) Representative current traces (averages of 5 trials), elicited by voltage ramps (500 ms duration), in $\beta 2-\mathrm{V} 287 \mathrm{~L}$ or CTRL mice, as indicated. The ramps between -85 and $-40 \mathrm{mV}$ are relative to adult mice. The ramp between -80 and $-20 \mathrm{mV}$ is relative to a $\mathrm{P} 8$ mouse. The background current was always subtracted to the current measured in the presence of GABA. (B) Average $E_{G A B A}$ values at the indicated stages, in CTRL and $\beta 2-V 287 L$ mice. Detailed statistics are given in the main text.

mice. A more complex pattern was displayed by KCC2. In WT mice, KCC2 was found in VLG and RT as early as E14-E15, and conspicuous expression was observed at birth in all TH nuclei (Table 1). Its amount remained relatively stable thereafter, except in RT, where a transient KCC2 decrease was observed at the end of the first postnatal weeks, in both WT (Table 1) and transgenic mice (see text). Although no other systematic comparison of the KCC2 distribution in mouse $\mathrm{TH}$ is available, previous evidence also points to early KCC2 expression in TH nuclei (Hübner et al., 2001; Li et al., 2002; Wang et al., 2002; Stein et al., 2004; Horn et al., 2010; Markkanen et al., 2014). This likely reflects the quicker time course of thalamic circuit wiring, which is complete by P14-P15 (Amadeo et al., 2001). In fact, $\left[\mathrm{Cl}^{-}\right]_{\mathrm{i}}$ is essentially stable by the second postnatal week in rat VB (Glykys et al., 2009). More specifically, the so-called relay nuclei (comprising the anterior region), show a rapid maturation that reflects the early establishment of the connections implicated in sensory map topography (Lopez-Bendito and Molnár, 2003). By contrast, the adult $\mathrm{RT}$ is characterized by a weaker KCC2 immunolabeling compared with the more caudal adjacent relay nuclei (Barthó et al., 2004). Our results show that such difference is not precocious, but is caused by a postnatal decrease of KCC2 in RT. Although little is known about the development of synaptic connections in RT (Amadeo et al., 2001; Nagaeva and Akhamadeev, 2006; Hou et al., 2016), we hypothesize that proper synaptogenesis here requires $\mathrm{KCC} 2$ amounts similar to those present in other TH nuclei. Subsequently, KCC2 would stabilize at lower levels in the adult RT, where $\mathrm{E}_{\mathrm{GABA}}$ is more depolarized than in relay cells (Ulrich and Huguenard, 1997; Barthó et al., 2004; Sun et al., 2013), and the reciprocal GABAergic connections lead to excitatory effects (Sun et al., 2012).

\section{Cellular distribution of NKCC1 and KCC2 in neocortex and thalamus}

In neocortex and $\mathrm{TH}$, our confocal and ultrastructural analysis showed wide expression of NKCC1 in neurons, axons, synaptic terminals and astrocytes in agreement with previous results (Hübner et al., 2001; Yan et al., 2001; Wang et al., 2002). NKCC1 was mainly found in the apical dendrites of cortical pyramidal neurons and in myelinated fiber bundles in $\mathrm{TH}$, suggesting that specific mechanisms of NKCC1 regulation operate in distinct neuronal compartments (Hübner et al., 2001; Yan et al., 2001). Moreover, electron and confocal microscopy revealed NKCC1 in synaptic terminals. In particular, NKCC1 was found in glutamatergic (VGLUT1+) terminals, especially in adult PFC. In contrast, NKCC1 was rarely found in GABAergic (VGAT +) terminals, except in developing $\mathrm{TH}$. The study of NKCC1 expression and 
function in presynaptic terminals is still in its infancy. Physiological evidence indicates that presynaptic NKCC1 can stimulate (Bos et al., 2011) as well as inhibit (Shen et al., 2013) neurotransmitter release, making it difficult to provide a general interpretation of our results. In immature rat spinal cord, NKCC1 activity enhances transmitter release from afferent fibers by favoring a GABAdependent presynaptic depolarization (Bos et al., 2011). We can hypothesize that a similar mechanism is operant in the developing $\mathrm{TH}$, thus facilitating the usual depolarizing role of GABA in early stages. In contrast, NKCC1 has been found to inhibit glutamate release in photoreceptors (Shen et al., 2013), a mechanism worth further investigation in the PFC VGLUT1 + terminals.

At variance with NKCC1, the cellular distribution of KCC2 was different in cortical and $\mathrm{TH}$ neurons. In neonatal neocortex, $\mathrm{KCC} 2$ was mainly localized in cell bodies of pyramidal and GABAergic neurons. During the first postnatal week, KCC2 shifted to cell membranes and dendrites, even though a significant amount of the transporter was retained on the surface of pyramidal neurons' somata. This presumably reflects the high density of GABAergic synapses around pyramidal cell bodies. Such a pattern is broadly similar to the one observed in other species (Stein et al., 2004; Dzhala et al., 2005; Li et al., 2007; Hyde et al., 2011; Kovács et al., 2014). On the contrary, the KCC2 immunoreactivity of TH nuclei at birth was much closer to the adult's; this is consistent with the concept that, in rodents, KCC2 appears earlier in the $\mathrm{TH}$ anlage than in neocortex. The KCC2 + outlines observed around pyramidal cell bodies were absent or discontinuous in cortical and TH GABAergic cells, where KCC2 immunoreactivity was mainly confined to the dendrites. We attribute such difference to the relatively low average density of reciprocal GABAergic terminals among inhibitory interneurons in neocortex and TH (Pi et al., 2013; Hou et al., 2016; Aracri et al., 2017).

\section{The effect of $\beta 2-V 287 L$ on cotransporters' amounts and the GABAergic switch}

In rodent neocortex, the $\mathrm{nAChR}$ subunit expression peaks in the second postnatal week, and recent lines of evidence indicate that synaptic maturation is regulated by both $\alpha 7$ - and $\beta 2$-containing nAChRs (Molas and Dierssen, 2014). Because the maximal nAChR expression is concomitant with the GABAergic switch, we studied if $\beta 2-\mathrm{V} 287 \mathrm{~L}$ affected the $\mathrm{Cl}^{-}$cotransporters. Between the first and the second postnatal week, the increase of KCC2 expression was delayed by $\beta 2-\mathrm{V} 287 \mathrm{~L}$, in PFC layer $\mathrm{V}$. Since the effect was not accompanied by any alteration of NKCC1, we expected mice expressing $\beta 2-V 287 \mathrm{~L}$ to also display a more depolarized $\mathrm{E}_{\mathrm{GABA}}$, around P8. In fact, the GABAergic switch was delayed in these animals. Our data suggest that a regulatory interaction occurs between KCC2 and heteromeric nAChRs during synaptogenesis. The specific effect observed in layer $\mathrm{V}$ is consistent with the fact that, in this layer, the action of $\mathrm{ACh}$ is dominated by $\beta 2$-containing $\mathrm{nAChRs}$ (Aracri et al., 2013; Poorthuis et al., 2013). Previous work also showed that expression of $\beta 2-\mathrm{V} 287 \mathrm{~L}$ does not change the amount of heteromeric nAChRs on the plasma membrane (Manfredi et al., 2009). Therefore, we attribute the action of the mutant subunit to the functional alterations it produces on nAChRs, rather than to an overall alteration of $\mathrm{nAChR}$ expression. Both $\beta 2-$ containing nAChRs (Lozada et al., 2012; Molas and Dierssen, 2014) and KCC2 (Li et al., 2007; Fiumelli et al., 2013) regulate the formation and maturation of dendritic spines by mechanisms that are thought to involve the actin cytoskeleton. Because activating $n A C h R s$ leads to both membrane depolarization and $\mathrm{Ca}^{2+}$ influx, hyperfunctional mutant receptors containing $\beta 2-\mathrm{V} 287 \mathrm{~L}$ (De Fusco et al., 2000) could alter KCC2 expression by interfering with calcium signals. An alternative explanation is based on the finding that $\beta 2-\mathrm{V} 287 \mathrm{~L}$, as well as other ADNFLE mutations, favors the assembly of the highaffinity $(\alpha 4)_{2}(\beta 2)_{3} \mathrm{nAChR}$ stoichiometry with respect to the low affinity $(\alpha 4)_{3}(\beta 2)_{2}$ subtype (Son et al., 2009). One can hypothesize that the altered proportion of stoichiometric forms, besides altering the receptor's response to the agonist, could modify the $\mathrm{nAChR}$ binding to some regulatory element of the dendritic spine machinery, or possibly to KCC2 itself.

Irrespective of the molecular mechanism, the effect we observed around P8 was transient. At P60, the amount of $\mathrm{KCC} 2$ in PFC layer $\mathrm{V}$ was higher in $\beta 2$ V287L mice, even though $E_{\mathrm{GABA}}$ was similar in adult mice carrying or not the transgene. Because layer $V$ is highly susceptible to develop seizures (Telfeian and Connors, 1998), we hypothesize that the steady-state increase of KCC2 in the mutant is a compensatory mechanism. A higher local $\mathrm{Cl}^{-}$turnover would be necessary to sustain inhibition in an overactive network, and prevent a significant alteration of the steady state $\mathrm{Cl}^{-}$levels. This explanation would be consistent with the observation that in chronic epileptic conditions (Pathak et al., 2007; Karlócai et al., 2016), or peritumoral tissue (Conti et al., 2011), the KCC2 amounts usually increase, which points to a long-term compensation of hyperexcitability. In fact, deleting $\mathrm{KCC} 2$ in mice facilitates epileptiform activity (Woo et al., 2002; Tornberg et al., 2005), and mutations impairing KCC2 are linked to human epilepsy (Kahle et al., 2014; Puskarjov et al., 2014). It must be however recalled that the physiological meaning of the changes of KCC2 expression observed in epileptic networks is complex and still controversial, as the observed effects depend on the pathophysiological context and the studied region. For example, in temporal lobe, acutely induced epileptiform activity (Rivera et al., 2002; Wake et al., 2007; Puskarjov et al., 2012), and the induction of status epilepticus (Pathak et al., 2007; Li et al., 2008; Barmashenko et al., 2011) produce a chronic decrease of KCC2 surface expression, which is attributed to the action of higher calpain levels (Kaila et al., 2014b).

As for the thalamic effects of mutant $n A C h R s$, mice bearing $\beta 2-\mathrm{V} 287 \mathrm{~L}$ displayed a lower KCC2 level in the mature RT nucleus. Differently from the GABAergic cells in adult PFC, in which the somatic expression of nAChRs is population-specific (Aracri et al., 2017), the GABAergic RT neurons in mice express a relatively high 
density of postsynaptic $\alpha 4 \beta 2 \mathrm{nAChRs}$. These can effectively trigger action potentials, when the cholinergic afferents are activated (Sun et al., 2013). Therefore, hyperfunctional mutant nAChRs could over-stimulate RT neurons and boost calcium signaling therein. As discussed earlier, this could favor a calpain-dependent KCC2 downregulation. Such a mechanism could also be facilitated by the typical propensity of RT cells to enter into burst-like firing states (Fogerson and Huguenard, 2016).

\section{CONCLUSION}

The retardation of the GABAergic switch we observed in the PFC of mice carrying $\beta 2-V 287 L$ suggests that the pathogenetic mechanism in ADNFLE comprises physiological alterations during synaptogenesis that are likely to depend on the integrity of GABAergic signaling. In the adult, complex alterations of KCC2 expression were observed in the PFC and RT nucleus of mice expressing the transgene. Understanding the precise functional meaning of these alterations will require deeper studies on the thalamocortical excitability of these mice. Nonetheless, the fact that no such alteration was observed in SS cortex and the other TH nuclei is consistent with the hypothesis that the effect of $\beta 2$ V287L is specifically related to frontal hyperexcitability during sleep.

\section{ACKNOWLEDGMENTS}

This work was supported by Telethon Italy [GGP12147], the University of Milano-Bicocca [FAR 2015-2016], and the University of Firenze (ex $60 \%$ funds). The funding sources had no involvement in study design; in the collection, analysis and interpretation of data; in the writing of the report; and in the decision to submit the article for publication. Aurora Coatti and Simone Brusco were fellows of the PhD Program in Molecular and Translational Medicine (DIMET), of the University of Milano-Bicocca. Debora Modena is fellow of the PhD Program in Integrative Biomedical Research of the University of Milano. The authors are grateful to Dr. Francesca Mattevi and Carlotta Donati for help during the preparation and analysis of brain sections.

LC, AA (Florence), and AC maintained transgenic animals and selected CTRL and $\beta 2-V 287 L$; PA, MEP, $\mathrm{DI}$ and DM performed immunohistochemical experiments and analyses; MA acquired images and set the protocols for densitometric analysis; AC, SB, SM carried out electrophysiological analyses; AA (Milan) and $A B$ analyzed the results and wrote the paper. All authors contributed to design the experiments and discuss the results.

\section{DECLARATIONS OF INTEREST}

None.

\section{REFERENCES}

Amadeo A, Ortino B, Frassoni C (2001) Parvalbumin and GABA in the developing somatosensory thalamus of the rat: an immunocytochemical ultrastructural correlation. Anat Embryol 203:109-119.

Aracri P, Consonni S, Morini R, Perrella M, Rodighiero S, Amadeo A, Becchetti A (2010) Tonic modulation of GABA release by nicotinic acetylcholine receptors in layer $\mathrm{V}$ of the murine prefrontal cortex. Cereb Cortex 20:1539-1555.

Aracri P, Amadeo A, Pasini ME, Fascio U, Becchetti A (2013) Regulation of glutamate release by heteromeric nicotinic receptors in layer $\mathrm{V}$ of the secondary motor region (Fr2) in the dorsomedial shoulder of prefrontal cortex in mouse. Synapse 67:338-357.

Aracri P, Banfi D, Pasini ME, Amadeo A, Becchetti A (2015) Orexin (hypocretin) regulates glutamate input to fast-spiking interneurons in layer $\mathrm{V}$ of the $\mathrm{Fr} 2$ region of the murine prefrontal cortex. Cereb Cortex 25:1330-1347.

Aracri P, Meneghini S, Coatti A, Amadeo A, Becchetti A (2017) A4ß2* nicotinic receptors stimulate GABA release onto fast-spiking cells in layer $\mathrm{V}$ of mouse prefrontal (Fr2) cortex. Neuroscience 340:48-61.

Aronica E, Boer K, Redeker S, Spliet WG, van Rijen PC, Troost D, Gorter JA (2007) Differential expression patterns of chloride transporters, $\mathrm{Na}+-\mathrm{K}+-2 \mathrm{Cl}-$ cotransporters and $\mathrm{K}+-\mathrm{Cl}-$ cotransporter, in epilepsy-associated malformations of cortical development. Neuroscience 145:185-196.

Awad PN, Sanon NT, Chattopadhyaya B, Carriço JN, Ouardouz M, Gagné J, Duss S, Wolf D, Desgent S, Cancedda L, Carmant L, Di Cristo G (2016) Reducing premature KCC2 expression rescues seizure susceptibility and spine morphology in atypical febrile seizures. Neurobiol Dis 91:10-20.

Barmashenko G, Hefft S, Aertsen A, Kirschstein T, Köhling R (2011) Positive shifts of the $G_{A B A}$ receptor reversal potential due to altered chloride homeostasis is widespread after status epilepticus. Epilepsia 52:1570-1578.

Barthó P, Payne JA, Freund TF, Acsády L (2004) Differential distribution of the $\mathrm{KCl}$ cotransporter $\mathrm{KCC} 2$ in thalamic relay and reticular nuclei. Eur J Neurosci 20:965-975.

Becchetti A, Aracri P, Meneghini S, Brusco S, Amadeo A (2015) The role of neuronal nicotinic acetylcholine receptors in autosomal dominant nocturnal frontal lobe epilepsy. Front Physiol 6:22.

Ben-Ari Y, Gaiarsa JL, Tyzio R, Khazipov R (2007) GABA: a pioneer transmitter that excites immature neurons and generates primitive oscillations. Physiol Rev 87:1215-1284.

Bolte S, Cordelières FP (2006) A guided tour into subcellular colocalization analysis in light microscopy. J Microsc 224:213-232.

Bos R, Brocard F, Vinay L (2011) Primary afferent terminals acting as excitatory interneurons contribute to spontaneous motor activities in the immature spinal cord. J Neurosci 31:10,184-10,188.

Cancedda L, Fiumelli H, Chen K, Poo MM (2007) Excitatory GABA action is essential for morphological maturation of cortical neurons in vivo. J Neurosci 27:5224-5235.

Chen H, Luo J, Kintner DB, Shull GE, Sun D (2005) $\mathrm{Na}(+)$ dependent chloride transporter (NKCC1)-null mice exhibit less gray and white matter damage after focal cerebral ischemia. $J$ Cereb Blood Flow Metab 25:54-66.

Clayton GH, Owens GC, Wolff JS, Smith RL (1998) Ontogeny of cation- $\mathrm{Cl}^{-}$cotransporter expression in rat neocortex. Brain Res Dev Brain Res 109:281-292.

Conti L, Palma E, Roseti C, Lauro C, Cipriani R, de Groot M, Aronica E, Limatola C (2011) Anomalous levels of $\mathrm{Cl}^{-}$transporters cause a decrease of GABAergic inhibition in human peritumoral epileptic cortex. Epilepsia 52:1635-1644.

De Fusco M, Becchetti A, Patrignani A, Annesi G, Gambardella A, Quattrone A, Ballabio A, Wanke E, Casari G (2000) The nicotinic receptor $\beta 2$ subunit is mutant in nocturnal frontal lobe epilepsy. Nat Genet 26:275-276.

Dzhala VI, Talos DM, Sdrulla DA, Brumback AC, Mathews GC, Benke TA, Delpire E, Jensen FE, Staley KJ (2005) NKCC1 transporter facilitates seizures in the developing brain. Nat Med 11:1205-1213. 
Fiumelli H, Woodin MA (2007) Role of activity-dependent regulation of neuronal chloride homeostasis in development. Curr Opin Neurobiol 17:81-86.

Fiumelli H, Briner A, Puskarjov M, Blaesse P, Belem BJ, Dayer AG, Kaila K, Martin JL, Vutskits L (2013) An ion transport-independent role for the cation-chloride cotransporter $\mathrm{KCC} 2$ in dendritic spinogenesis in vivo. Cereb Cortex 23:378-388.

Fogerson PM, Huguenard JR (2016) Tapping the brakes: cellular and synaptic mechanisms that regulate thalamic oscillations. Neuron 92:687-704.

Franklin KBJ, Paxinos G (2008) The mouse brain in stereotaxic coordinates. 3rd ed. San Diego (CA): Academic Press. p. 256.

Ge S, Goh EL, Sailor KA, Kitabatake Y, Ming GL, Song H (2006) GABA regulates synaptic integration of newly generated neurons in the adult brain. Nature 439:589-593.

Glykys J, Dzhala VI, Kuchibhotla KV, Feng G, Kuner T, Augustine G, Bacskai BJ, Staley KJ (2009) Differences in cortical versus subcortical GABAergic signaling: a candidate mechanism of electroclinical uncoupling of neonatal seizures. Neuron 63:657-672.

Graziano A, Liu XB, Murray KD, Jones EG (2008) Vesicular glutamate transporters define two sets of glutamatergic afferents to the somatosensory thalamus and two thalamocortical projections in the mouse. J Comp Neurol 507:1258-1276.

Horn Z, Ringstedt T, Blaesse P, Kaila K, Herlenius E (2010) Premature expression of $\mathrm{KCC} 2$ in embryonic mice perturbs neural development by an ion transport-independent mechanism. Eur J Neurosci 31:2142-2155.

Hou G, Smith AG, Zhang ZW (2016) Lack of intrinsic GABAergic connections in the thalamic reticular nucleus of the mouse. J Neurosci 36:7246-7252.

Hübner CA, Lorke DE, Hermans-Borgmeyer I (2001) Expression of the $\mathrm{Na}-\mathrm{K}-2 \mathrm{Cl}$ cotransporter NKCC1 during mouse development. Mech Dev 102:267-269.

Hyde TM, Lipska BK, Ali T, Mathew SV, Law AJ, Metitiri OE, Straub RE, Ye T, Colantuoni C, Herman MM, Bigelow LB, Weinberger DR, Kleinman JE (2011) Expression of GABA signaling molecules KCC2, NKCC1, and GAD1 in cortical development and schizophrenia. J Neurosci 31:11088-11095.

Jensen FE (2011) Epilepsy as a spectrum disorder: implications from novel clinical and basic neuroscience. Epilepsia 52(Suppl 1):1-6.

Kahle KT, Merner ND, Friedel P, Silayeva L, Liang B, Khanna A, Shang Y, Lachance-Touchette P, Bourassa C, Levert A, Dion PA, Walcott B, Spiegelman D, Dionne-Laporte A, Hodgkinson A, Awadalla P, Nikbakht H, Majewski J, Cossette P, Deeb TZ, Moss SJ, Medina I, Rouleau GA (2014) Genetically encoded impairment of neuronal KCC2 cotransporter function in human idiopathic generalized epilepsy. EMBO Rep 15:766-774.

Kaila K, Price TJ, Payne JA, Puskarjov M, Voipio J (2014a) Cationchloride cotransporters in neuronal development, plasticity and disease. Nat Rev Neurosci 15:637-654.

Kaila K, Ruusuvuori E, Seja P, Voipio J, Puskarjov M (2014b) GABA actions and ionic plasticity in epilepsy. Curr Opin Neurobiol 26:34-41.

Karlócai MR, Wittner L, Tóth K, Maglóczky Z, Katarova Z, Rásonyi G, Erőss L, Czirják D, Halász P, Szabó G, Payne JA, Kaila K, Freund TF (2016) Enhanced expression of potassium-chloride cotransporter $\mathrm{KCC} 2$ in human temporal lobe epilepsy. Brain Struct Funct 221:3601-3615.

Khirug S, Ahmad F, Puskarjov M, Afzalov R, Kaila K, Blaesse P (2010) A single seizure episode leads to rapid functional activation of KCC2 in the neonatal rat hippocampus. J Neurosci 30:12028-12035.

Kovács K, Basu K, Rouiller I, Sík A (2014) Regional differences in the expression of $\mathrm{K}(+)-\mathrm{Cl}(-) 2$ cotransporter in the developing rat cortex. Brain Struct Funct 219:527-538.

Lacoh CM, Bodogan T, Kaila K, Fiumelli H, Vutskits L (2013) General anaesthetics do not impair developmental expression of the KCC2 potassium-chloride cotransporter in neonatal rats during the brain growth spurt. Br J Anaesth 110(Suppl 1):i10-i18.
Li H, Tornberg J, Kaila K, Airaksinen MS, Rivera C (2002) Patterns of cation-chloride cotransporter expression during embryonic rodent CNS development. Eur J Neurosci 16:2358-2370.

Li H, Khirug S, Cai C, Ludwig A, Blaesse P, Kolikova J, Afzalov R, Coleman SK, Lauri S, Airaksinen MS, Keinänen K, Khiroug L, Saarma M, Kaila K, Rivera C (2007) KCC2 interacts with the dendritic cytoskeleton to promote spine development. Neuron 56:1019-1033.

Li X, Zhou J, Chen Z, Chen S, Zhu F, Zhou L (2008) Long-term expressional changes on $\mathrm{Na}^{+}-\mathrm{K}^{+}-\mathrm{Cl}^{-}$co-transporter 1 (NKCC1) and $\mathrm{K}^{+}-\mathrm{Cl}^{-}$co-transporter 2 (KCC2) in $\mathrm{CA} 1$ region of hippocampus following lithium-pilocarpine induced status epilepticus (PISE). Brain Res 1221:141-146.

Liu Q, Wong-Riley MT (2012) Postnatal development of $\mathrm{Na}(+)-\mathrm{K}$ $(+)-2 \mathrm{Cl}(-)$ co-transporter 1 and $\mathrm{K}(+)-\mathrm{Cl}(-)$ co-transporter 2 immunoreactivity in multiple brain stem respiratory nuclei of the rat. Neuroscience 210:1-20.

Liu Z, Neff RA, Berg DK (2006) Sequential interplay of nicotinic and GABAergic signaling guides neuronal development. Science 314:1610-1613.

Lopez-Bendito G, Molnár Z (2003) Thalamocortical development: how are we going to get there? Nat Rev Neurosci 4:276-289.

Lozada AF, Wang X, Gounko NV, Massey KA, Duan J, Liu Z, Berg DK (2012) Induction of dendritic spines by $\beta 2$-containing nicotinic receptors. J Neurosci 32:8391-8400.

Manfredi I, Zani AD, Rampoldi L, Pegorini S, Bernascone I, Moretti M, Gotti C, Croci L, Consalez GG, Ferini-Strambi L, Sala M, Pattini L, Casari G (2009) Expression of mutant $\beta 2$ nicotinic receptors during development is crucial for epileptogenesis. Hum Mol Genet 18:1075-1088.

Mansvelder HD, Role LW (2006) Neuronal receptors for nicotine: functional diversity and developmental changes. In: Miller MW, editor. Brain development. Normal processes and the effects of alcohol and nicotine. New York: Oxford University Press. p. 404.

Markkanen M, Karhunen T, Llano O, Ludwig A, Rivera C, Uvarov P, Airaksinen MS (2014) Distribution of neuronal KCC2a and KCC2b isoforms in mouse CNS. J Comp Neurol 522:1897-1914.

Marty S, Wehrlé R, Alvarez-Leefmans FJ, Gasnier B, Sotelo C (2002) Postnatal maturation of $\mathrm{Na}^{+}, \mathrm{K}^{+}, 2 \mathrm{Cl}^{-}$cotransporter expression and inhibitory synaptogenesis in the rat hippocampus: an immunocytochemical analysis. Eur J Neurosci 15:233-245.

Molas S, Dierssen M (2014) The role of nicotinic receptors in shaping and functioning of the glutamatergic system: a window into cognitive pathology. Neurosci Biobehav Rev 46:315-325.

Nagaeva DV, Akhamadeev AV (2006) Structural organization, neurochemical characteristics, and connections of the reticular nucleus of the thalamus. Neurosci Behav Physiol 36: 987-995.

Pathak HR, Weissinger F, Terunuma M, Carlson GC, Hsu FC, Moss SJ, Coulter DA (2007) Disrupted dentate granule cell chloride regulation enhances synaptic excitability during development of temporal lobe epilepsy. J Neurosci 27:14012-14022.

Pi HJ, Hangya B, Kvitsiani D, Sanders JI, Huang ZJ, Kepecs A (2013) Cortical interneurons that specialize in disinhibitory control. Nature 503:521-524.

Plotkin MD, Snyder EY, Hebert SC, Delpire E (1997) Expression of the $\mathrm{Na}-\mathrm{K}-2 \mathrm{Cl}$ cotransporter is developmentally regulated in postnatal rat brains: a possible mechanism underlying GABA's excitatory role in immature brain. J Neurobiol 33:781-795.

Poorthuis RB, Bloem B, Schak B, Wester J, de Kock CP, Mansvelder HD (2013) Layer-specific modulation of the prefrontal cortex by nicotinic acetylcholine receptors. Cereb Cortex 23:148-161.

Puskarjov M, Ahmad F, Kaila K, Blaesse P (2012) Activity-dependent cleavage of the $\mathrm{K}-\mathrm{Cl}$ cotransporter KCC2 mediated by calciumactivated protease calpain. J Neurosci 32:11356-11364.

Puskarjov M, Seja P, Heron SE, Williams TC, Ahmad F, lona X, Oliver KL, Grinton BE, Vutskits L, Scheffer IE, Petrou S, Blaesse P, Dibbens LM, Berkovic SF, Kaila K (2014) A variant of KCC2 from patients with febrile seizures impairs neuronal $\mathrm{Cl}^{-}$extrusion and dendritic spine formation. EMBO Rep 15:723-729. 
Rivera C, Voipio J, Payne JA, Ruusuvuori E, Lahtinen H, Lamsa K, Pirvola U, Saarma M, Kaila K (1999) The $\mathrm{K}^{+} / \mathrm{Cl}^{-}$co-transporter $\mathrm{KCC} 2$ renders GABA hyperpolarizing during neuronal maturation. Nature 397:251-255.

Rivera C, Li H, Thomas-Crusells J, Lahtinen H, Viitanen $T$, Nanobashvili A, Kokaia Z, Airaksinen MS, Voipio J, Kaila K, Saarma M (2002) BDNF-induced TrkB activation down-regulates the $\mathrm{K}^{+}-\mathrm{Cl}^{-}$cotransporter $\mathrm{KCC} 2$ and impairs neuronal $\mathrm{Cl}^{-}$ extrusion. J Cell Biol 159:747-752.

Sedmak G, Jovanov-Milošević N, Puskarjov M, Ulamec M, Krušlin B, Kaila K, Judaš M (2016) Developmental expression patterns of KCC2 and functionally associated molecules in the human brain. Cereb Cortex 26:4574-4589.

Shen W, Purpura LA, Li B, Nan C, Chang IJ, Ripps H (2013) Regulation of synaptic transmission at the photoreceptor terminal: a novel role for the cation-chloride co-transporter NKCC1. J Physiol 591:133-147.

Shouse MN, Quigg MS (2008) Chronobiology. In: Engel JJ, Pedley TA, editors. Epilepsy: a comprehensive textbook, vol. vol 2. Philadelphia: Lippincott Williams and Wilkins. p. 1961-1974.

Son CD, Moss FJ, Cohen BN, Lester HA (2009) Nicotine normalizes intracellular subunit stoichiometry of nicotinic receptors carrying mutations linked to autosomal dominant nocturnal frontal lobe epilepsy. Mol Pharmacol 75:1137-1148.

Stein V, Hermans-Borgmeyer I, Jentsch TJ, Hübner CA (2004) Expression of the $\mathrm{KCl}$ cotransporter $\mathrm{KCC} 2$ parallels neuronal maturation and the emergence of low intracellular chloride. $J$ Comp Neurol 468:57-64.

Steinlein OK, Mulley JC, Propping $\mathrm{P}$, Wallace RH, Phillips HA, Sutherland GR, Scheffer IE, Berkovic SF (1995) A missense mutation in the neuronal nicotinic acetylcholine receptor $\alpha 4$ subunit is associated with autosomal dominant nocturnal frontal lobe epilepsy. Nat Genet 11:201-203.

Sun YG, Wu CS, Renger JJ, Uebele VN, Lu HC, Beierlein M (2012) GABAergic synaptic transmission triggers action potentials in thalamic reticular nucleus neurons. J Neurosci 32:7782-7790.

Sun YG, Pita-Almenar JD, Wu CS, Renger JJ, Uebele VN, Lu HC, Beierlein M (2013) Biphasic cholinergic synaptic transmission controls action potential activity in thalamic reticular nucleus neurons. J Neurosci 33:2048-2059.

Takayama C, Inoue Y (2010) Developmental Iocalization of potassium chloride co-transporter 2 (KCC2), GABA and vesicular GABA transporter (VGAT) in the postnatal mouse somatosensory cortex. Neurosci Res 67:137-148.
Talos DM, Sun H, Kosaras B, Joseph A, Folkerth RD, Poduri A, Madsen JR, Black PM, Jensen FE (2012) Altered inhibition in tuberous sclerosis and type Ilb cortical dysplasia. Ann Neurol 71:539-551.

Telfeian AE, Connors BW (1998) Layer-specific pathways for the horizontal propagation of epileptiform discharges in neocortex. Epilepsia 39:700-708.

Tinuper P, Bisulli F, Cross JH, Hesdorffer D, Kahane P, Nobili L, Provini F, Scheffer IE, Tassi L, Vignatelli L, Bassetti C, Cirignotta F, Derry C, Gambardella A, Guerrini R, Halasz P, Licchetta L, Mahowald M, Manni R, Marini C, Mostacci B, Naldi I, Parrino L, Picard F, Pugliatti M, Ryvlin P, Vigevano F, Zucconi M, Berkovic S, Ottman R (2016) Definition and diagnostic criteria of sleeprelated hypermotor epilepsy. Neurology 86:1834-1842.

Tornberg J, Voikar V, Savilahti H, Rauvala H, Airaksinen MS (2005) Behavioural phenotypes of hypomorphic KCC2-deficient mice. Eur J Neurosci 21:1327-1337.

Ulrich D, Huguenard JR (1997) Nucleus-specific chloride homeostasis in rat thalamus. J Neurosci 17:2348-2354.

Wake H, Watanabe M, Moorhouse AJ, Kanematsu T, Horibe S, Matsukawa N, Asai K, Ojika K, Hirata M, Nabekura J (2007) Early changes in KCC2 phosphorylation in response to neuronal stress result in functional downregulation. J Neurosci 27:1642-1650.

Wang C, Shimizu-Okabe C, Watanabe K, Okabe A, Matsuzaki H, Ogawa T, Mori N, Fukuda A, Sato K (2002) Developmental changes in KCC1, KCC2, and NKCC1 mRNA expressions in the rat brain. Brain Res Dev Brain Res 139:59-66.

Woo NS, Lu J, England R, McClellan R, Dufour S, Mount DB, Deutch AY, Lovinger DM, Delpire E (2002) Hyperexcitability and epilepsy associated with disruption of the mouse neuronal-specific $\mathrm{K}-\mathrm{Cl}$ cotransporter gene. Hippocampus 12:258-268.

Yamada J, Zhu G, Okada M, Hirose S, Yoshida S, Shiba Y, Migita K, Mori F, Sugawara T, Chen L, Liu F, Yoshida S, Ueno S, Kaneko S (2013) A novel prophylactic effect of furosemide treatment on autosomal dominant nocturnal frontal lobe epilepsy (ADNFLE). Epilepsy Res 107:127-137.

Yan Y, Dempsey RJ, Sun D (2001) Expression of $\mathrm{Na}(+)-\mathrm{K}(+)-\mathrm{Cl}(-)$ cotransporter in rat brain during development and its localization in mature astrocytes. Brain Res 911:43-55.

Zhu L, Polley N, Mathews GC, Delpire E (2008) NKCC1 and KCC2 prevent hyperexcitability in the mouse hippocampus. Epilepsy Res 79:201-212.

(Received 8 January 2018, Accepted 18 June 2018) (Available online 24 June 2018) 